\title{
Yes/no Questions in Mandarin Chinese Revisited ${ }^{*}$
}

\author{
Horst-Dieter Gasde \\ Zentrum für Allgemeine Sprachwissenschaft (ZAS) Berlin \\ gasde@zas.gwz-berlin.de
}

This article discusses some syntactic peculiarities of Chinese yes/no questions. Starting from the observation that Standard Mandarin shares significant typological features with prototypical SOV languages, Chinese is treated as an underlyingly verb-final language. Based on this heuristic principle, A-not- $\mathrm{AB}, \mathrm{AB}$-not-A and $\mathrm{AB}$-not questions are uniformly derived by means of one simple raising rule that operates within the sentence constituent $V^{\prime}$. This novel idea is elaborated on in great detail in the first part of the article. In contrast to the prevailing trend, it is argued that the question operator contained in A-not-A and A-not sentences CANNOT be raised to "Comp". In consequence, A-not-A and A-not questions are "typed" in the head position of a sentence-internal functional phrase that we call Force2 Phrase (F2P) in the present paper. This position is not to be confused with Drubig's (1994) Polarity1 Phrase (Pol1P), in the head position of which assertive negations and an abstract affirmative element are located. The existence of a head position $\mathrm{F} 2^{\circ}$ other than Pol $1^{\circ}$ is supported by the fact that $\mathrm{F} 2^{\circ}$ can be occupied by certain overt question operators, such as assertive shi-bu-shi, which are compatible with negations. In contrast to the assertive question operator shi-bu-shi which is obligatorily associated with information focus, non-assertive shi-bu-shi serves as a compound focus and question operator whose focus feature is complex insofar as it is composed of two subfeatures: a contrastivity and an exhaustivity subfeature. Non-assertive shi-bu-shi is obligatorily associated with identificational focus in the sense of Kiss (1998). In accordance with some basic ideas of Chomsky's checking theory, the two subfeatures of the complex focus feature carried by the non-assertive shi-bu-shi operator check a correlating subfeature in the head position of a corresponding functional phrase (Contrastive Phrase and Focus Phrase, respectively). The question feature contained in the non-assertive shi-bu-shi operator is attracted by the head of Forcel Phrase (Fi') at the level of LF. Due to the fact that $\mathrm{Fl}^{\circ}$ is sentence-final, the question feature of non-assertive shi-bu-shi must be Chomsky-adjoined to F1'. Unlike identificational focus phrases which are inherently contrastive, topics are non-contrastive in the default case. As separate speech acts, they are located in a c-commanding position outside the sentence structure. Semantically, there is a difference between Frame-Setting Topics and Aboutness Topics. As shown in the article, both A-not-A and A-not questions on the one hand and yes/no questions ending with ma on the other can be used in neutral and non-neutral contexts. The decisive advantage of ma questions, however, is that their question operator has scope over the whole sentence.

\footnotetext{
The present paper has been written within the context of the DFG project 'Syntax of C-Domain' launched at the Zentrum für Allgemeine Sprachwissenschaft, Typologie und Universalienforschung (ZAS), Berlin, in co-operation with the research group 'Sprachtheoretische Grundlagen der Kognitionswissenschaft' at the Universität Leipzig. The participants in the ongoing project are André Meinunger, Kerstin Schwabc, and the author of this paper. I am very grateful to Anita Steube and Bernhard Drubig for many ycars of support which have greatly stimulated this project. In addition, I am indebted to Marie-Claude Paris, Xu Liejiong, Liu Danqing and Ewald Lang, who provided enlightening and thoughtful comments on previous versions of this paper. Last but not least, I owe a special debt to Paul David Doherty for his careful revision of this text.
} 


\section{Introduction}

\subsection{Sentential Force in natural languages}

Natural languages make use of various universal strategies in expressing 'sentential force' in the sense of Chierchia \& McConnell-Ginet (1990).

In the simplest case, sentential force, i.e. the semantic correlate of 'sentence type', is made manifest by means of intonation contour and word order. This case is realized, for example, in all Germanic languages, where a combination of rising final intonation and verb-subject word order is operative in yes/no questions. Furthermore, sentential force can be denoted morphologically. Russian imperative sentences, for instance, display distinctive morphological forms on the verb involved. Moreover, sentential force can be signaled by certain lexical elements, such as special particles. An example would be the role of enclitic $l i$ in interrogative sentences of Russian and other Slavic languages, not to mention the role of clausal typing particles in numerous East and South East Asian languages. Finally, sentential force can be expressed by affixes, phonological alternations and missing elements.

In view of the syntactic, morphological, lexical and prosodic resources of languages, it is not a surprising fact that, despite certain similarities with regard to the presentation of declarative, interrogative and imperative sentences, we can find important differences between various languages in the system of sentence types, especially as far as the specificity of functions within a particular sentence type is concerned. ${ }^{1}$

The present paper deals with Chinese yes/no questions.

Unlike wh-questions and disjunctive questions ${ }^{2}$, yes/no questions can be conceived as a request that the person you are addressing should tell you whether the proposition you have supplied him is true or not ${ }^{3}$.

Based on the dimension of the regular association of 'form' and 'use', there are at least three different subtypes of yes/no questions, which shall be discussed in this paper.

\subsection{A proposal for a discourse-based model of Chinese sentences}

My subsequent syntactic descriptions are based on the following model of the Chinese sentence:

\section{(1.1) TOPIC $>$ F1' $>$ FocP $>$ IP $>$ ContrP $>$ F2P $>$ PolP $>V^{\prime}$}

with $>$ for 'preceding + dominating', F1 for 'Force1', FocP for 'Focus Phrase', IP for 'Infl(ection) Phrase', ContrP for 'Contrastivity Phrase', F2P for 'Force2 Phrase', PolP for 'Polarity Phrase', and V for 'verb / predicative adjective'.

\footnotetext{
Cf. Sadock and Zwicky (1985), p. 160.
}

2 Disjunctive questions, which consist of two yes/no questions connected by the element $o r$, are often called 'alternative questions'. Disjunctive questions and wh-questions share the feature that they cannot be answered with 'yes' or 'no'.

3 Cf. Sadock \& Zwicky (1985), p. 155. Following Groenendijk \& Stokhof (1997: 1072), I start from the position that a question requires a change in information ABOUT THE WORLD, but not a CHANGE IN THE WORLD ITSELF. Given this, asking a question is a basic speech act. But see Vanderveken's (1990) typology, according to which asking a question belongs to the basic speech act type of directives: 'I (hereby) ask you to answer (the question) Q'. As for details about the different 'pragmatic' and 'semantic' approaches to the interrogatives see Groenendijk \& Stokhof (1997). 
In this model, only the constituent $\mathrm{V}^{\prime}$ headed by a verb or a predicative adjective is obligatory in every complete sentence.

1.2.1. IP is only projected in categorial sentences. This is due to the fact that categorial sentences express an overt predication relation between an initial constituent functioning as a 'notional subject', and the subsequent sentence part functioning as a 'notional predicate'. Kiss (1994) claims that 'topic-prominent' languages realize categorial and thetic judgments in different syntactic structures. Whereas in categorial judgements the subject argument of the verb appears in a VP-external position, thetic judgements are expressed in structures in which all arguments of the verb remain within VP. Provided that this is correct, Chinese is a topic-prominent language needing IP to accommodate the unmarked syntactic subject in categorial sentences. ${ }^{4}$ More precisely, I reason that spec-IP is a topic-position reserved for the unmarked subject in active sentences and the direct object in passive structures.

Nevertheless, the claim that the Chinese sentence contains an Inflection Phrase is problematic in some ways, since Chinese has neither verb-subject agreement nor a morphological category of Tense. ${ }^{5}$ Moreover, there is no distinction between finite and non-finite clauses in Chinese, as demonstrated by Xu (1985/86: 346ff.; 1994: 323ff.) and Y. Huang (1994: 27-33, 157ff., 265f.). ${ }^{6}$ Y. Huang (2000: 37) concludes that "there are only finite clauses in Chinese". 7

1.2.2. $\mathrm{F} 1$ ' is the functional phrase where information about whether a given sentence is a statement, a question, a command etc. is located in the default case. One typological peculiarity of Chinese is that the head of this phrase, as an immediate result of its rightperipheral position, does not project a Spec position ${ }^{8}$. A second typological peculiarity of Chinese is that A-not-A and A-not questions are typed in the head position of a

4 Contrary to categorial sentences, thetic sentences do not express predication about something or somebody. Compare the categorial sentence (i) containing an IP with the thetic sentence (ii) lacking an IP:

(i) Keren lai-le.

guest come-Asp

"The guest has come'

(ii) Duimian lai le yi qun haizi.

over there come PART one group children

'There is a group of children coming over there.'

As for the difference between categorial and thetic judgements, cf. von der Gabelentz (1901: 369f., 372), Kuroda (1972-73), and Sasse (1987), for example.

5 Concerned with different quantifier scope facts characteristic of English and Chinese, Aoun \& $\mathrm{Li}$ (1989: 152; 1993: 22f.) argue that subjects in English are generated at D-structure in the Spec of VP position and raised to the Spec of Infl position at $S$-structure, whereas subject raising is not available in Chinese because of the "degenerate nature of Infl" in this language. So the subject is base-generated in Spec of VP position and stays in this position at S-structure. In contrast, Hornstein (1995: 164f.) claims that Chinese subjects are directly generated in Spec ArgS, without a copy in VP-internal position.

6 See also Y. Huang $(1995 ; 2000)$. Contrary to this, C.-T. J. Huang $(1984 ; 1987 ; 1989)$ and others tried to show that a difference between finite and non-finite sentences does exist. Their examples and test criteria, however, were disproved by $\mathrm{Y}$. Huang and $\mathrm{Xu}$.

7 Y. Huang's position is indeed the most plausible conclusion compared with the two alternatives: (i) there are neither finite nor non-finite clauses in Chinese; (ii) there are only non-finite clauses in Chinese.

8 In this respect, I follow Whitman (1997), cf, section 7. 
clause-internal functional phrase that I will call F2P. This phrase is head-initial, unlike F1'. Both functional phrases, F1' and F2P, are in complementary distribution, for every sentence must be typed ${ }^{9}$, but no sentence can be typed twice.

These assumptions conflict with Rizzi's (1997: 287) tenet that the force-finiteness system as the essential part of the $C$ system is present in all "non-truncated clausal structures". ${ }^{10}$ Furthermore, these assumptions are at variance with Huang (1982), Li (1992) and Ernst (1994) who postulate that the question operator in A-not-A questions must raise to Comp at LF. Finally, our assumptions deviate from the approach of Schaffar \& Chen (2001) who accommodate the illocutionary question operator contained in A-not-A questions in Drubig's (1994: 23) Polarityl Phrase (Pol1P). In contrast to Schaffar and Chen, I will argue that illocutionary operators on the one hand and elements like assertive negation (bu/mei) on the other should not be accommodated in the same functional head position, even more so since they are not strictly complementary, as I will show.

1.2.3. In connection with identificational foci in the sense of Kiss (1998), FocP and the functional Middle Field category ContrP pertain to the focus-background system of the sentence structure. As such, they are present "only if "needed"" (Rizzi 1997: 288).

1.2.4. Following Lippert (1965), Altmann (1981), Jacobs (1984), and Krifka (2000; 2001b), TOPICS are perceived as separate speech acts. Consequently, I claim that they are located outside the sentence structure, though in a c-commanding position.

1.2.5. (1.1) is a strictly discourse-oriented sentence model predicated on the Strong Lexicalist Hypothesis.

Rizzi (1997: 281) suggests that any structural presentation of a clause consists of three layers: 1. the lexical layer headed by the verb, the structural layer, in which theta assignment takes place, 2. the inflectional layer, headed by functional heads corresponding to concrete or abstract morphological specifications on the verb, and responsible for the licensing of argumental features such as case and agreement, 3 . the complementizer layer containing a force-finiteness system ${ }^{11}$ and a topic-focus system.

Following Rizzi, Platzack (1999) advocates a model where a V-domain, an I-domain and a C-domain exchange information with systems of thought via the designated interfaces Thematic Form (TF), Grammatical Form (GF) and Discourse Form (DF). Whereas at TF thematic information is exchanged, and at GF grammatical meanings are exchanged, DF is the interface level at which pragmatic information and information regarding sentence type is exchanged.

Similarly, Grohmann (2000) splits the clause into three domains with a $\theta$-domain for thematic relations, a $\varphi$-domain for agreement properties and a $\omega$-domain for discourse information.

9 Cf. Chomsky \& Lasnik (1977: 445) and Cheng (1991).

10 A-not-A and A-not yes/no questions are by no means truncated structures.

11 According to Rizzi, ForceP is considered as the interface between a propositional content expressed by IP and the superordinate structure (a higher clause or the discourse), whereas FinP "faces inside" expressing a distinction related to finiteness (ibid., p. 283f.). As mentioned above, a clear-cut distinction hetween finiteness and non-finiteness in Chinese clauses does not exist. I infer from this that FinP as a special functional projection is "not needed" in Chinesc. 
It seems, however, that Rizzi's, Platzack's and Grohmann's assumptions are too strong. In fact, all of the domains suggested are interspersed with elements conveying information that is associated with categories like force-finiteness and topic-focus, as we will see in this paper.

\subsection{Organization of the paper}

The present paper is organized as follows:

The first two sections lay out the specific background which my subsequent claims about major properties of A-not-A and A-not questions will be based on: Section 2 is mainly devoted to the discussion of some typological peculiarities of Chinese. The section starts from certain SOV remains in Pre-Qin Chinese, SOV tendencies in Northern dialects, and significant features shared by prototypical SOV languages and Standard Mandarin. Based on the preposition-postposition parameter, Chinese is described as a postpositional language. It ensues that Chinese is treated as an underlyingly verb-final language in section 3.

In section 4, I argue for a unified derivation of A-not-AB, AB-not-A and $A(B)$-not questions. This novel conception conflicts with the influential approach of Huang (1991). Moreover, I claim that A-not-A and A-not questions are "typed" in a sentenceinternal functional head position other than Poll $1^{\circ}$, a position introduced by Drubig (1994) to accommodate an (abstract) affirmative element and (assertive) negations. In contrast to the prevailing trend, it is further argued that the question operator in A-not-A and A-not sentences cannot be raised to "Comp". This implies that F1' is not projected in A-not-A and A-not questions, differently from yes/no questions ending with the question particle $m a$.

My postulate that A-not-A and A-not questions contain an abstract question feature $<\mathrm{Q}>$ in $\mathrm{F} 2^{\circ}$ is underpinned by additional evidence provided in section 5, where I focus attention on some overt question operators, which are all located in $\mathrm{F} 2^{\circ}$, as I contend. One of them is the assertive question operator shi-bu-shi.

In section 6 , the role of non-contrastive and contrastive topics in Chinese yes/no questions is considered. Topics are divided into two basic types: Frame-Setting Topics and Aboutness Topics.

Section 7 is about the properties and the syntactic anchoring of identificational focus phrases in Chinese yes/no questions. The section concentrates on the compound focus and question operator shi-bu-shi, not to be confused with assertive shi-bu-shi. I posit that the focus feature carried by non-assertive shi-bu-shi is composed of a contrastivity feature, [+contr], and an exhaustivity feature, $[+\mathrm{exh}]$, checking a correlating feature in the head position of ContrP and FocP, respectively, a procedure that may happen at Sstructure or at LF. The question feature of this operator is claimed to undergo LF raising in the result of which it is Chomsky-adjoined to F1'. There is no sentence position in which identificational focus phrases uniformly occur, as the S-structural positions of subjects, direct objects and adjuncts marked by the shi-bu-shi operator at issue show.

In section 8, the pragmatic use of A-not-A questions and ma questions is discussed. It is claimed that both types of yes/no questions can be used in neutral and non-neutral contexts. However, ma questions have the decisive advantage of their question operator having scope over the whole sentence. 


\section{Chinese as a postpositional language}

My proposal for a uniform derivation of all A-not-A and A-not questions which shall be described in section 3 is predicated on the hypothesis that Chinese is a postpositional language with an OV word order at the level of D-structure. This section aims to give reasons for this hypothesis.

\subsection{SOV remainders in Pre-Qin Chinese and SOV tendencies in northern dialects}

Liu (2000) claims that Chinese has never been a typical SVO language, though SVO has been the basic order in Chinese clauses since its earliest record. As elaborated by Liu, Pre-Qin Chinese contained remains of an earlier SOV word order manifesting themselves by the preverbal position occupied by interrogative pronouns and pronouns in negative sentences. With reference to the fact that Chinese is closely related to the Tibeto-Burman languages which essentially are SOV languages, Liu speculates that the common protolanguage of Chinese and today's Tibeto-Burman languages may have been an SOV language ${ }^{12}$. As for Modern Chinese, the author comes to the conclusion that the so-called $b a$-construction, which came into existence in the $7^{\text {th }} / 8^{\text {th }}$ centuries and has been predominantly marking direct objects since the beginning of the $17^{\text {th }}$ century ${ }^{13}$, makes Chinese look like a very untypical SVO language ${ }^{14}$. In this connection, he mentions SOV orders in the Qinghai Xining dialect of Chinese that can only be explained by the influence of Tibetan and some neighboring Altaic languages (p. 56). In this respect, Liu follows Light (1979: 163) who also connected the word order features of Modern Chinese with influences of neighboring languages. Light points out that Tai language SVO tendencies are reflected in southern dialects, such as Cantonese and Southern Min, whereas Altaic SOV tendencies are reflected in Mandarin.

Likewise, Hawkins (1983) characterizes Chinese as a language with SOV/SVO features. Kroch (2001: 706) states that "languages like Chinese or Yiddish show an apparent mix of headedness at the clausal level, so that there is even controversy over whether they are VO or OV".

\subsection{SOV features of Standard Mandarin}

2.2.1. Referring to the 45 universal tendencies correlated with SOV, SVO and VSO orders ascertained by Greenberg (1966) on the basis of a sample of 30 languages (which, interestingly enough, does not contain Chinese), Tai ( 1985: 345f. $[=1973$ : 663]) claims that Chinese is an SOV language. He especially stresses the point that the following word order features can be generalized under one single general syntactic principle, the principle that SOV languages tend to place restricting elements before restricted elements: A. relative clause before noun, B. adjective before noun, C. genitive before the governing noun, D. adverbial before the main verb, E. adverb before adjective, F. proper noun before common noun. Tai notes that those and other grammatical features of Chinese consistently appear in rigid SOV languages such as Japanese and Turkish.

\footnotetext{
12 Ibid., p. 53.

13 See also Wang Li (1958: 4131f.), Ohta (1987; 1991), Peyraube (1989), and Bisang (1991).

i4 Cf. Liu (2000), p. 54.
} 
Given fact A it is not surprising that Downing (1978: 383), Mallinson \& Blake (1981) and Dryer (1992), treating Chinese as an SVO language, are forced to describe Chinese relative clauses as an exception. Dryer (1992: 86), whose empirical results are based on word order properties of 625 languages ${ }^{15}$, sees "evidence of a very strong tendency for VO languages to be NRel: RelN order is found in only one genus (Chinese), while NRel order is found in 60 other genera". Mallinson \& Blake (1981: 442) note: "Chinese is an $S$ VO language, more or less, with preposed relatives, though it is true that such a type of language is rare."

2.2.2. In addition to the SOV features of Chinese listed so far, there are further crucial word order features shared by Chinese and prototypical SOV languages. Two of them are reflected in the use of sentence-final yes-no question particles and the fact that whphrases remain in situ.

C. L. Baker (1970: 206f.) was the first to observe the relationship between these two facts. Based on Greenberg's (1966) data, Baker hypothesized: First, no language can have a rule which moves the questioned constituent to clause-initial position, but regularly positions all morphemes for yes-no questions in clause-final position. Second, no language can have a rule which moves a questioned constituent to sentence-final position, even if the Q morpheme occurs there. Referring to this hypothesis, Chomsky (1973: 234) posits that only languages with clause-initial COMP permit a COMP substitution transformation. ${ }^{16}$

\subsection{The preposition-postposition parameter}

Greenberg (1966) employed three sets of order to establish his 'basic order typology': first, the existence of prepositions and postpositions, second, the relative order of subject, verb and object (reduced to the common types VSO, SVO and SOV), and third, the position of qualifying adjectives.

Modifying Greenberg's (1966) second criterion, Hawkins (1983) postulates that the word order SVO is not a reliable typological indicator. In that "SVO does not correlate with other word order properties in Greenberg's data in a unique and principled way"17, it even undermines the generality of a verb-based typology. Contrary to the ambivalent SVO order, VSO and SOV are type indicators (though limited ones). Yet what has precedence over all the others in Hawkins' theory is a word order typology based on the preposition-postposition parameter. Consequently, he claims that there exist two major word order types, namely prepositional and postpositional languages, each of them having certain unique families of word order combinations.

\subsection{The role of postpositions in Modern Chinese}

Contrary to Travis (1984), Ernst (1988) and A. Li (1990), who, more or less explicitly, negate the existence of postpositions in Chinese, I will contend that Modern Chinese, in

15 Dryer's method involves first grouping the languages into genetic groups, referring to each of these groups as a GENUS. These genera are then grouped into six large geographical areas (ibid., p. 83ff.).

16 Following Chomsky (1973), Huang (1981/82: 409, fn.6) claims that COMP is a universal element that may appcar in various sentence positions: "It should be noted for all our purposes it is not necessary that the COMP be assumed to be clause-initial. All that is necessary is that there is a COMP position c-commanding S."

17 Hawkins (1983), p. 29 . 
essence, is a postpositional language. The need of postpositions has been caused by the strong tendency of Chinese to place restricting elements before restricted elements.

2.4.1. Liu (2000) notes that the fact that postpositions play an important role in the grammar of Modern Chinese is underestimated by many researchers. In contrast, Liu gives a detailed picture of the role of different types of postpositions in the syntactic structure of Chinese sentences. As he elaborated, Chinese postpositions function as 'relators', thereby realizing the 'relator principle' investigated by Dik (1997). According to Dik, a 'relator' links two constituents to each other, having its preferred position between the two relata. ${ }^{18}$ In Modern Chinese, relators mainly appear either on the border of an attribute (the dependent) and a noun (the center) or on the border of a preverbal adjunct (the dependent) and a verb (the center). While the corresponding relator in the former case is represented by the postposition de, the situation is more complicated in the latter case.

2.4.2. As pointed out by Liu (2000), the latter type of postposition can be traced back to two major historical sources: relational nouns on the one hand and adverbs on the other.

Originally, relational nouns expressed a location, such as $l i$ ('inner lining'), zuo ('left hand'), zhong ('center of a circle (occupied by a flagpole)'), shang ('top part') etc. Later, they were affected by a process of grammaticalization in the result of which they could no longer be used as independent syntactic units. Today, they are tied to fixed positions (just as other function words are). More precisely, they are obligatorily combined with nouns (or noun phrases) preceding them. The meaning of the nominal unit preceding a postposition can even be abstract. Owing to the semantic depletion which Chinese postpositions were subject to ${ }^{19}$, the semantic differences between them dwindled to such an extent that they can sometimes be replaced with each other, as (2.1a,b) illustrate:

(2.1) a. $\begin{aligned} & \text { zai di-shang zuo } \\ & \text { in ground-above sit } \\ & \text { 'be sitting on the ground' }\end{aligned}$
b. zai di-xia zuo
in ground-below sit
'be sitting on the ground'
c.
$\begin{aligned} & \text { *zai di zuo } \\ & \text { in ground sit }\end{aligned}$

Lacking a postposition filling the relator position, $(2.1 \mathrm{c})$ is absolutely ungrammatical.

By the same token, xin-shang ('heart-above'), xin-zhong ('heart-center'), xin-li ('heartinside'), and xin-xia ('heart-below') have the same meaning: 'in one's heart'. Telling examples for the combination of postpositions with abstract nouns are: sixiang-li ('in one's thinking'), xingdong-shang ('in one's actions'), and fazhan-zhong ('in (a process of) development').

\footnotetext{
18 As for Dik's relator principles, cf. also Siewierska (1988; 1991).

19) This process went hand in hand with a reduction of their suprasegmental structure, mainly characterized by the loss of their etymological tone.
} 
The second historical source of postpositions operating on the border of adjuncts and predicates in Modern Chinese are elements that stem from adverbs, as in:

(2.2) a. Ta (xiang) huli side/yiyang jiaohua.

he like fox similarly sly

'He is as sly as a fox.'

b. Ta (xiang) hua yiyang/yiban/ban meili.

she like flower similarly beautiful

'She is as beautiful as a flower.'

Whereas the use of the preposition xiang ('like') is optional, the postpositions side, yiyang, and yiban (shortened: ban), respectively, cannot be omitted in this structure.

Liu (2000) suggests that Chinese postpositions project a postpositional phrase which is embedded in a prepositional phrase, yielding a structure which I will illustrate with the help of zai di-shang ('on the ground'):

$$
\begin{aligned}
& {\left[\mathrm { PP } \text { Zai } \left[\mathrm{PostpP}_{\mathrm{P}}^{[\mathrm{DP} \text { di] }}\right.\right. \text { shang]] }} \\
& \text { in } \quad \text { ground above }
\end{aligned}
$$

\subsection{Chinese prepositions are coverbs}

2.5.1. Although lexical elements like zai ('in') in (2.1) and xiang in (2.2) are often considered as 'prepositions', Chinese is by no means a 'prepositional language' in the sense of Hawkins (1983). The overwhelming majority of Prep languages in Hawkins' Expanded Sample is distinguished by the feature combination 'NG \& NRel' ${ }^{20}$, while Chinese lacks this feature combination ${ }^{21}$.

Both facts clearly show that 'Prep' does not function as a "major typological indicator, $^{22}$ in Modern Chinese.

2.5.2. Actually, all 'prepositions' of Modern Chinese arise out of full verbs previously used in serial verb constructions, where they became subject to a process of grammaticalization which is not yet finished. Despite the fact that their grammaticalization has progressed differently, they should better be described as 'coverbs', as done by Paul (1982), C. Lehmann (1982), Chu (1983), Bisang (1991; 1992), Gasde (1993) and others, or as 'verb-prepositions', as done by Dragunov (1960[1952]). The verbal historical background of modern "prepositions" is effortlessly recognizable because some of them still carry aspect suffixes distinctive of verbs. The most striking example is the coverb dui ('towards'), which can be combined with the durative-progessive suffix $z$, he the perfective suffix $l e$ and the experiential suffix guo, such as in dui-zhe/le/guo wo xiao ('smile to me') ${ }^{23}$. Some of the lexical elements in question have a fullverb and a coverb meaning, such as zai ('be in' vs. 'in'), gei ('give'

20 Cf. Hawkins (1983), p. 73. 'NG' stands for the word order Noun-Genitive, while 'NRel' stands for Noun-Relative Clause.

21 To be more precise, Chinese has neither NG (because it is a caseless language) nor the word order NPoss (Noun-Possessive).

22 Cf. ibid., p. 115.

23 Cf. Chu (1983), p. 72. 
vs. 'for') and gen ('follow' vs. 'with'). In special cases, one and the same sentence can have a coverb and a full verb reading:

(2.4) Ni gen wo zou!

yOL GEN I go

a. Follow me!

b. Go with me.

But the most tangible proof of the non-prepositional status of Chinese coverbs is the fact that nearly all of them, e.g. yong ('using', 'with the help of'), dao ('going to', 'leaving for'), zai ('(being) in'), gen ('following', 'with'), gei ('giving', 'for'), and cong ('from') are compatible with the A-not-A form (more precisely, with the subpattern Anot-AB) in yes/no questions. See the following example:

(2.5) Ni cong-bu-cong Beijing qu Shanxi?

you from-not-from Beijing go Shanxi

'Do you from Beijing go to Shanxi?'

Paul (1982: 123f.) holds the view that the special character of coverbs can be adequately described only by means of a scale with verb and preposition as its poles. She summarizes that $b a$ displays almost no verbal behavior, thus advancing towards the prepositional end of the scale ${ }^{24}$, whereas the verbal character of yong ("using, with the help of') is remarkably strong.

In discussing the historical development of coverbs, Y. C. Li (1980) notes that in Early Archaic Chinese a few coverbs with 'broad' meanings were gradually replaced by many coverbs with specific properties. According to Li, the number proliferated to sixty in Modern Chinese. Some of them, such as zai, cong, yong, ha and others, have been utilized throughout the history of the Chinese language.

\subsection{Summary}

To recapitulate this section, the strong tendency to place restricting elements before restricted elements, the use of sentence-final particles, the fact that wh-phrases remain in situ, and the dominant role of postpositions are the most striking SOV features of Mandarin Chinese.

\section{Chinese as an underlyingly verb-final language}

As we have learned in section 2, Chinese is a postpositional language exhibiting major typological features of rigid SOV languages such as Japanese, Korean and Turkish. I consider this to be a warrant for treating Chinese as an underlyingly verb-final lan-

$24 B a$ is often regarded as a pure marker of the direct object or as a case marker. But see the sections 4.3 and 5.2.2, where we treat $b a$ as a dummy verb syntactically licensing the direct object of the sentence. 
guage, being perfectly aware of the fact that at the level of S-structure the unmarked word order is SVO. ${ }^{25}$

In addition, I will follow Fukui \& Speas (1986: 128) who postulate that functional categories project to $X^{\prime \prime}$, while all projections of lexical categories are $X^{\prime}$. This idea implies that $\mathrm{X}^{\prime \prime}$ structures projected by functional categories are limited to a single specifier position and a single complement position, whereas the $X^{\prime}$ projections of lexical categories are indefinitely iterable, limited only by the Projection Principle and other independent principles of licensing. ${ }^{26}$ In consequence, Chinese predicates merely contain $V^{\prime}$ projections in my system.

Given these two preconditions, the abstract D-structure of a predicate phrase headed by a three-place verb like song ('give') is (3.1):

$$
\left[\mathrm{v}^{\prime} \mathrm{SU}\left[\mathrm{v}^{\prime} \mathrm{IO}\left[\mathrm{v}^{\prime} \mathrm{DO} \mathrm{V^{ \circ }}\right]\right]\right]
$$

So far, I am in accordance with Koopman (1984) and A. Li (1990) who propose a headfinal structure of VP as well. Yet whereas Koopman and Li achieve the S-structural word order by NP movement, i.e. by moving the objects from the left side of the verb to its right side ${ }^{27}$, I suppose that in (3.1) the verb must be raised into head positions of higher V'-shells in the sense of Larson (1988; 1990), yielding the S-structure (3.2):

$$
\left[x P U_{1}\left[v^{\prime} t_{1}\left[v^{\prime}\left[v^{\circ} V_{2}^{0}\right]\left[v^{\prime} \text { IO }\left[v^{\prime}\left[v^{\circ} t_{2}^{\prime}\right]\left[v^{\prime} D O t_{2}\right]\right]\right]\right]\right]\right]
$$

This derivation involves the idea that $\theta$-role assignment and Syntactic Licensing of verb arguments ${ }^{28}$ are two independent syntactic procedures, which can take place at different levels of the derivation of sentences and which can be opposed with respect to their direction. That is to say, along the lines of the syntactic model outlined by (3.1)/ (3.2), the verb is enabled to assign $\theta$-roles from the right to the left at the level of D-structure, while Syntactic Licensing ${ }^{29}$ goes from the left to the right and takes place at S-structure.

25 Mulder \& Sybcsma (1992) make the pretence of having evidence that Chinese is a VO language at Dstructurc. In fact, the notion of D-structure is a construct. Hence, the syntactic structures assumed at this abstract level can hardly be 'right' or 'wrong'. Rather, they can serve as a heuristic means. In this sense, the problem is with the help of which assumptions one can explain more phenomena of Chinese grammar than by means of others. Thereforc, with respect to the question of whether Chinese at Dstructure should be treated as a VO language or as an OV language, neither the Small Clause analysis suggested by Mulder \& Sybesma for certain sentences nor the analysis of A-not-A and A-not questions which I will propose in section 4 can have the status of 'evidence'. In truth, both approaches are no more than hypotheses.

26. This approach has been called the 'Relativized X'-Theory'. As for the development of this theory, see also Fukui (1991), Fukui \& Saito (1992), Saito \& Fukui (1998) and Fukui (2001).

27 As for that procedure, cf. Goodall (1990: 246), who points out that such argument movement from one side of the head to the other leads to theory-internal and conceptual difficulties, besides the fact that there is very little empirical support for such kinds of movement.

28 In inflectional and agglutinating languages, Syntactic Licensing corresponds to the operation of Case assignment. Our conviction that only in languages with a case morphology Syntactic Licensing is taking place by Case assignment, is supported by (Kiparsky (1991: 1): "Abstract Case and AGR (syntactic elements assumed to be present in all languages independently of morphology) do not exist."

29 Cf. Koopman (1984: 124), who claims that in Chinese "Case" is assigned to the right. 
For the DO to be licensed, the verbal element $V^{0}$ has to move to the $V^{\prime}$-shell head position marked with $t_{2}$. Having licensed the $D O$ from this position, the verb moves on to the lowest V'-shell head position c-commanding the IO. From there, it licenses the IO.

In Chinese, $V^{\circ}$ is strictly tied to $V^{\prime}$, i.e. it can neither be raised to $I^{\circ}$ since Infl is a deficient category in Chinese (as outlined in section 1.3.1), nor can it be raised to Force $1^{\circ}$ since Force $1^{\prime}$ is head-final (cf. section 4.4.2 and section 7.2.4).

As for the subject (in active sentences), no syntactic licenser is required, just as the subject in nominative-accusative languages does not need any authority assigning it the nominative. ${ }^{30}$

The stem of Chinese verbs can commonly be followed by certain (semi-)suffixes and other elements such as non-referential objects, all of them being constitutive components of the head constituent $\mathrm{V}^{\circ}$. In other words, the head constituent $\mathrm{V}^{\circ}$ can consist of a Verbal Complex (VC) with the stem of the verb in the leftmost position of $\mathrm{V}^{\circ}$.

\section{A-not-A and A-not questions}

Keeping in mind the assumptions about the internal structure of $V^{\prime}$ made in the above section, let's turn our attention towards the construction of yes/no questions of the types A-not-A and A-not.

\subsection{The data}

The element $\mathrm{A}$ as a constitutive element of the A-not-A pattern is thought of as a label for several predicative categories, such as verb, adjective, modal, copula, coverb, and even postverbal manner adverbial. ${ }^{31}$ In A-not-AB, 'B' stands for 'direct object'.

4.1.1. In connection with a direct object selected by a transitive verb, the A-not-A pattern can assume the forms ' $\mathrm{V}$-not-VO' as in (4.1) or 'VO-not-V' as in (4.2):
(4.1) $\mathrm{Ni}$ kan-bu-kan dianying?
you watch-not-watch movic
'Do you watch the movie?'

(4.2) Ni kan dianying bu-kan? you watch movie not-watch 'Do you watch the movie?'

In Standard Mandarin, the choice of negation, including that in the A-not-A pattern, depends on the aspect of the verb.

In 'zero-marking' sentences ${ }^{32}$, the selected negation normally is $b u$, such as illustrated in (4.1) and (4.2).

If the Verb, however, is marked as aspectually perfective by the preverbal particle $y o u^{33}$ or as carrying the experiential aspect, then the selected negation will be mei. In the

30 According to Falk (1991: 1991.), in languages like English or German, nominative case is not actually a case, for nouns (or NPs) used in isolation (in the 'citation form') are nominative, and there is, naturally, no source for casc to be assigned to a form in isolation.

3I In the A-not pattern, however, the element A can only be represented by verbs (sce below).

32 Cl. Klein et al. (2000), p. $765 \mathrm{ff}$.

33 Wang (1965) was the first to assume that the verb-suffix -le occurring in affirmative sentences and the preverbal particle you occurring in negative sentences are allomorphs of a perfective morpheme. In terms of Huang (1988: 282), that is to say: "Wang observed that the two elements -le and you, both 
latter case, the case of experiential aspect, the verb is simultaneously marked by the preverbal particle you and the verb suffix guo.

He (1998: 4f.) gives some telling examples of the interaction of aspect and negation in the A-not-A pattern $\mathrm{V}$-not-VO, which is characterized by an almost bewildering variety of forms ${ }^{34}$ :

$$
\begin{array}{ccll}
\text { a. Ta lai-mei-(you)lai } & \text { Meiguo? } \\
\text { b. he come-not-(you)come } & \text { America } \\
& \text { Ta laile-mei-(you)lai } & \text { Meiguo? } \\
& \text { he } & \text { come }{ }_{1-\text {-not-(You)come }} & \text { America }
\end{array}
$$

- a \& b: 'Has he arrived in America?'
a. Ta lai-mei-(you)laiguo
Meiguo?
he come-not-(YOU)come ${ }_{\text {Givo }}$
America
b. Ta laiguo-mei-(you)laiguo Meiguo? he come ${ }_{\text {GLO }}$-not-(YOU)come $\mathrm{GUO}_{\mathrm{O}}$ America

- a \& b: 'Has he been to America?'

(4.5) Ta laiguole-mei-(you)laiguo Meiguo?

he come GUO-IE-not-(YOU)come $_{\text {GUO }}$ America

'Has he ever been to America?'

As the above examples show, the preverbal element you is incorporated in the A-not-A pattern. In negative declarative sentences, however, the preverbal element you may appear in positions that are non-adjacent to the verb. Consider a sentence like the following where a manner adverbial intervenes between the perfective element you and the verb kan 'read':

(4.6) Wo guji ta genben mei you haohaor kan zhe ben shu.

I guess he at all not you carefully read this CL book

'I guess he did not carefully read this book at all.'

It turns out that the perfective element you is not a prefix of the verb.

4.1.2. According to Klein \& Li \& Hendriks (2000: 728, 743), aspect expresses a temporal relation between the time at which the situation (process, state, event) described by the sentence obtains (the 'time of situation', abbreviated T-SIT), on the one hand, and the time about which something is asserted by the sentence (the 'topic time', abbreviated $\mathrm{TT}$ ), on the other.

Based on this time-relational definition of aspect, Klein et al. claim that Chinese aspectual particles "assert that TT precedes, follows, includes, or is included in the time

having a meaning and function similar to that of the perfective aspect, are in complementary distribution."

34 Recall that in declaratives the affirmative form of a perfective predicate is $\mathrm{V}$-le, while the negative one is mei-V. On the other hand, the negative form of $\mathrm{V}$-guo is mei-V-guo. As the example (4.5) exhibits, the experiential aspect can occur in combination with the perfective aspect. Notice further that the preverbal clement you can be deleted at the level of PF. I have slightly modified He's notation. 
of a situation described by the sentence" ${ }^{35}$. Klein et al. further claim that in the case of 2-phase predicates such as dao 'arrive' containing a 'source phase' during which someone 'is not at some place' and a 'target phase' during which this someone 'is at some place', the 'distinguished phase' (abbreviated DP) is the target phase in Chinese, in contrast to the English aspectual system in which the source phase is the DP.

Along the lines of this framework, the perfective aspect marker le signals that TT OVL PRETIME AND T-DP ${ }^{36}$. For a sentence like

(4.7) Zhang San zhongyu dao-le jia. (Klein et al. 2000: 758)

Zhan San finally arrive-LE home

'Zhang San finally arrived home.',

this means that T-DP as well as a subinterval of the source phase are included within TT. Klein et al. (2000: 758) illustrate this by means of the following diagram, in which ++++ indicates the distinguished phase, ..-- the source phase of 2-phase expressions, and [ ] the assertion time TT:

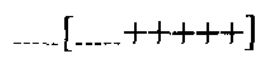

In contrast to $l e$, the experiential verb suffix guo "indicates that the time about which something is asserted falls into the posttime of the distinguished phase".37. Consider the following sentence given by Klein et al. (2000: 760):

(4.8) Zhang San chuguo-guo.

Zhang San go abroad-Guo

'Zhang San has been to other countries.'

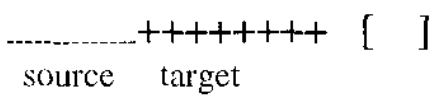

source target

In this sentence, both the source phase and the target phase precede TT, which means that the resulting state, Zhan San's being abroad, no longer obtains.

4.1.3. In contrast to the A-not-A pattern which, if filled with a transitive verb, permits the forms V-not-VO and VO-not-V, such as in (4.1) and (4.2), the A-not pattern is strongly tied to VO-not. That is to say, a question pattern like V-not-O in which the negator bu precedes the object does not exist, as indicated in (4.10):
(4.9) Ni kan dianyian bu?
you watch movic not
(4.10) $* \mathrm{Ni}$ kan-bu dianying?
you watch-not movie

'Do you watch the movie?'

At this point, it is important to point out that the A-not pattern is much more deeply rooted in the Chinese language than the A-not-A pattern. Whereas the A-not pattern can be traced back to Classical Chinese (Pre-Qin Dynasty to Han Dynasty), as noted by Cheng et al. (1996: 51), it took until the early Middle Ages (Sui and Tang Dynasties) that the A-not-A pattern came into use (cf. Ohta (1987: 378)). This means that the A-not pattern of the verb exemplified by the VO-not form kan dianying bu 'watch movie not' in the example (4.9) above is an independent pattern which cannot be derived from the VO-

\footnotetext{
35 Ibid., p. 753.

36 Cf. ibid., p. 754

37 Ibid., p. 759.
} 
not-V pattern (2.2), kan dianying bu kan 'watch movie not watch', by ellipsis (see also Shao (1996: 1 lof.)).

\subsection{A proposal for a unified derivation of A-not-A and A-not questions}

So far we have dwelt on the Chinese data. In this subsection, the problem of how the predicate of A-not-A and A-not questions is construed will be taken care of. As we will see, the analysis of the subpatterns (4.1), (4.2) and (4.9) exceedingly depends on the syntactic level one starts from.

4.2.1. Based on the Strong Lexicalist Hypothesis ${ }^{38}$, I propose that both in (4.1) and in (4.2) a 'morphological word" ${ }^{39}$, namely kan-bu-kan consisting of the verb stem kan 'watch' and the semi-suffix bu-kan, is directly inserted in the sentence at D-structure, while in (4.9) the same verb stem is followed by the semi-suffix $b u$. In connection with a supposed D-structural OV order, this involves that (4.1) and (4.2) share the Dstructure (4.11), whereas (4.9) is derived from a D-structure like (4.12):

(4.11) $\left[\mathrm{v}^{\prime}\right.$ ni $\left[\mathrm{V}^{\prime}\right.$ dianying kan-bu-kan $\left.]\right]$ you movie watch-not-watch

(4.12) $\left[\mathrm{v}^{\prime}\right.$ ni $\left[\mathrm{v}^{\prime}\right.$ dianying kan-bu]] you movie watch-not

Note that the sentence negation $b u$ is incorporated into the morphological word form $k a n-b u-k a n$ and $k a n-b u$, respectively.

With respect to the three examples under discussion, my basic idea is that semisuffixes can be 'taken along' or 'left behind' in the process of deriving the S-structure of sentences. Whereas in (4.1) the semi-suffix -bu-kan has been 'taken along' with the stem, it has been 'left behind' in (4.2). In (4.9), however, the semi-suffix -bu must be obligatorily 'left behind'.

Viewing this in connection with our assumptions in section 3 (cf., especially, (3.2)), the predicates of the examples concerned are shaped like this at the level of S-structure:

(4.1')
watch-not-watch
kan- $\mathrm{V}^{\prime}$ movie

(4.2') $\left[\mathrm{v}^{\prime} \mathrm{kan}_{1}\left[\mathrm{v}^{\prime}\right.\right.$ dianying $\mathrm{t}_{\mathrm{i}}-$ bu-kan $\left.]\right]$ watch movie not-watch

$\left(4.9^{\prime}\right) \quad\left[\mathrm{van}_{1}\left[\mathrm{v}^{\prime}\right.\right.$ dianying $\left.\left.\mathrm{t}_{1}-b u\right]\right]$
watch movie

The grammatical units kan-bu-kan in (4.11) and kan-bu in (4.12) are morphological words insofar as they cannot be freely interrupted by any lexical material, except for an object in cases like (4.2) and (4.9). That the object in (4.2) and (4.9) gets into a position in between the stem of the verb kan and its suffix is a result of the fact that the verb

38 Cf. Di Sciullo \& Williams (1987: 1): "Just as morphology has atoms, so does syntax, and words are commonly taken to be the atoms of syntax. We will call words in this sense syntactic atoms."

39) Cf. Wurzel (2000). 
stem moves into a higher $V^{\prime}$-shell for purposes of argument licensing, as depicted in section 3. In other words, the object is not 'inserted' in a position between the verb stem and its suffix(es) at D-structure.

The principles on which our analysis of (4.1), (4.2) and (4.9) is based also apply to He's (1998) examples (4.3) through (4.5) above. As for (4.3a), I claim that you is a constitutive element of the suffix complex of the verb, yielding the S-structure (4.3a'):

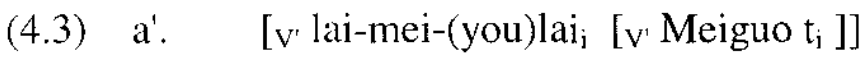

come-not-(YOU)come America

4.2.2. Considered from a pragmatic viewpoint, the $A-n o t-A B, A B-n o t-A$ and $A B$-not patterns are not pure duplicates of each other. Instead, they represent different regional variants.

Whereas the pattern $A$-not-AB is used in southern dialects, in the southern variety of Mandarin Chinese and in the standard variant of Mandarin, the pattern AB-not-A is used in the Beijing dialect and in the northern language area but not in the standard variant of Mandarin Chinese. The pattern $\mathrm{AB}$-not is used not only in the northern language area but also in various central and southern dialects, if '-not' is realized by $b u$. In short, in contrast to the pattern A-not-AB which occurs in Standard Mandarin, the patterns $\mathrm{AB}$-not- $\mathrm{A}$ and $\mathrm{AB}$-not have a regional slant. ${ }^{40}$

4.2.3. I would like to stress that a uniform derivation of yes/no questions based on the patterns V-not-VO, VO-not-V and VO-not will be impossible if Chinese is considered as a pure SVO language, as favored by Huang (1982; 1991), Mulder \& Sybesma (1992), Dai (1993), McCawley (1994), Ernst (1994), N. Zhang (1997), Sybesma (1999), Schaffar \& Chen (2001) and others.

Huang (1991) is forced to give different accounts for the patterns A-not-AB (V-notVO) exemplified by (4.1) and AB-not-A (VO-not-V) exemplified by (4.2). As for Anot- $\mathrm{AB}$, he proposes a morphological word formation mechanism involving a rule of verb copying followed by a rule inserting the negative morpheme 'not' bu. This mechanism fails, however, to work in the case of AB-not-A because of the intervening object which blocks a morphological derivation in Huang's system. Correspondingly, Huang derives the $\mathrm{AB}$-not-A pattern not by a morphological but by a syntactic rule. More precisely, he derives $A B$-not-A (VO-not-V) from the syntactic pattern $A B-n o t-A B$ (VO-not-VO) by 'anaphoric deletion'. This means that the predicate of a yes/no question like (4.2) would not have an S-structure like (4.2') given above but rather one like $\left(4.2^{\prime \prime}\right)$ :

\section{$\left(4.2^{\prime \prime}\right)$ [vp kan dianying] bu [vp kan dianying]}

watch movie not watch movie

Such an analysis directly leads to the conclusion that the AB-not-A pattern is 'more disjunctive' and 'less grammaticalized' than the A-not-AB pattern. ${ }^{41}$ Taking Huang's approach as their starting point, most of the authors concerned with A-not-A questions

\footnotetext{
40 I have to thank Professor Liu Danqing (Bcijing) for most of these facts (p.c.). See also Chen \& Schaffar (1997).

41 McCawley (1994), for example, differentiates between "two syntactically distinct types" which he calls 'reduplicative yes/no questions' and 'disjunctive yes/no questions', respectively (ibid., p. 179).
} 
restrict themselves to investigating the $\mathrm{A}$-not- $\mathrm{AB}$ pattern. Our conception is at variance with this prevailing trend.

4.2.4. Superficially, it seems that our analysis coincides with that of Huang, at least as far as the pattern A-not-AB is concerned. But on closer inspection, this turns out not to be the case. In the theoretical framework of Huang (1991), a [+Q] feature located in $\mathrm{Infl}^{\circ}$ and the naked stem of the verb are separately inserted in the sentence. Not until deriving the $S$-structure the $[+Q]$ feature triggers the copying of the verb stem and the insertion of a negation:

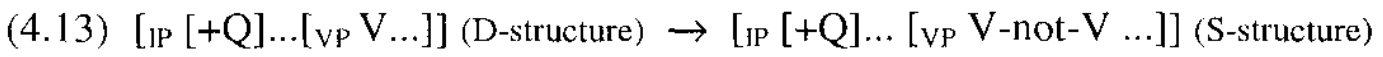

In our approach, however, a full morphological word form carrying a question feature $[+\mathrm{Q}]$ is inserted, yielding the D-structural predicate $(4.14)^{42}$ :

(4.14) $\left[\mathrm{v}^{\prime} \ldots\left[\mathrm{v}^{\prime} \mathrm{V}-\right.\right.$ not $\left.\left.-\mathrm{V}_{[+\mathrm{Q}]}\right]\right]$

4.2.5. To summarize the assumptions so far, I claim that the AB-not-A pattern is NOT 'more disjunctive' or 'less grammaticalized' than the A-not-AB pattern. Under a pragmatic viewpoint, the difference between $\mathrm{A}$-not- $\mathrm{AB}$ on the one hand and $\mathrm{AB}$-not- $\mathrm{A}$ and $\mathrm{AB}$-not on the other is that the the former is used predominantly in the standard variant of Mandarin Chinese, whereas the latter serve as dialectal variants of it.

My proposal that the A-not- $A B, A B-n o t-A$ and the $A B$-not patterns should be recognized as having the same grammatical status under a synchronic view is supported by the fact that all of them obey Island Constraints, as stated by Huang (1991: 31.3f.). In contrast, disjunctive patterns with the conjunction haishi 'or' do not exhibit island effects. That is to say, as opposed to the A-not-AB, AB-not-A and AB-not patterns, disjunctive patterns with haishi 'or' are able to appear in subject clauses and relative clauses. ${ }^{43}$

4.2.6. Some residual asymmetries between $A$-not- $A B$ and $A B$-not- $A$ questions on the one hand and $A B$-not questions on the other are mentioned in Cheng et al. (1996: section 1.1). These asymmetries concern, among others, the use of the element yijing 'already', which, according to the three authors, is compatible with the $\mathrm{AB}$-not pattern ${ }^{44}$ but not with $\mathrm{A}$-not-AB and $\mathrm{AB}$-not-A. As for the A-not pattern, they give the following example:

(4.15) ta yijing kan-wan shu meiyou?

(Cheng et al. 1996: 43, (7b))

he already read-finish book not-have

'Did he already finish reading the book?'

42 McCawley (1994: 180f.) correctly objects to Chomsky's (1991) treatment of the negative element in reduplicative questions as a fake negation rather than a real negation, i.e. as an element that does not appear in the decp structure. In our system, the negative element, incorporated in the morphological verb form, does appear at the level of D-structurc.

43 Interestingly enough, the syntactic pattern VP-not-VP representing a borderline type between disjunctive questions with haishi 'or' on the onc hand and A-not-A questions on the other does show island effects, as noted by Huang (1991: 313f.).

44 Cheng et al. call this pattern Negative Particle Questions (NPQs). 
Basically, this example represents just the perfective subvariant of the AB-not pattern. By contrast, the imperfective subvariant of the pattern is not compatible with the perfective aspect-like element yijing 'already':

(4.16) *Ni yijing kan dianyian bu?

you already watch movic not

'Do you already watch the movie?'

It is highly questionable whether the perfective variant of the AB-not pattern exemplified by (4.15) above belongs to the AB-not pattern at all:

While the A-not-A form of the verb is incompatible with the so-called $b a$-construc$\operatorname{tion}^{45}$, the perfective variant of the VO-not pattern is absolutely compatible, as (4.17) illustrates:

(4.17) Ni ba shu kanwan-le mei you?

you BA book read-finish-Asp not YOU

'Have you finished reading the book?'

Moreover, the perfective subpattern of AB-not, V-leO-mei you, can be utilized in the standard variant of Mandarin Chinese with no problems, while the imperfective subpattern of $\mathrm{AB}$-not (i.e. VO-bu) has a regional slant, as stated in section 4.2.2.

Provided that this is correct, then $\mathrm{A}(\mathrm{B})$-not is a purely imperfective pattern which, contrary to Cheng et al.'s (1996) claims, is just as incompatible with yijing 'already' as the A-not-AB and AB-not-A patterns. ${ }^{46}$

\subsection{Additional evidence for our proposal}

In section 3 I have hypothesized that internal arguments of the verb are licensed by moving the verb to c-commanding head positions of higher $V^{\prime}$-shells. In section 4.2 we have applied this principle to A-not-A and A-not predicates, postulating that the stem of the verb can 'take along' or 'leave behind' its suffixes in deriving the S-structure of a sentence. In this section, I will show that verb raising in A-not-A and A-not predicates is even obligatory, while it can be dispensed with in yes/no questions with ma, under certain conditions.

Let's come back to the fact that the A-not-A form of the verb is incompatible with the so-called $b a$-construction and compare the structures $(4.18 \mathrm{a}) /(4.19 \mathrm{a})$, which do not contain an A-not-A predicate, with those of $(4.18 \mathrm{~b}) /(4.19 \mathrm{~b})$ containing an A-not-A predicate, yielding ill-formed structures:

(4.18) a. Ni ba shu nazou-le ma? you BA book take away-AsP QP

'Have you taken away the book?'

b. *Ni ba shu nazou-mei- you nazou? you BA book take away-not- You take away

45 Cf. the next section, where the reasons for this incompatibility shall be explained.

46 Explicitly arguing with Cheng et al. (1996), N. Zhang (1997: 134f.) also strives to underline the common syntactic features shared by A-not-A and A-not questions. 
(4.19) a. Ni ba bilu sheng-le huo ma? ${ }^{47}$ you BA fireplace start-AsP fire $Q P$

'Did you fire up the fireplace?'

b. *Ni ba bilu sheng-mei- you sheng huo? you BA fircplace start-not- YOU start fire

My account for the difference in grammaticality of the above examples is that the raising of the verb is obviously blocked by the element $b a$ in the 'b.'-sentences.

As for the grammaticality of the 'a.'-sentences, I claim that the element $b a$, which we have called a 'coverb' in section 2.5 , is in truth a 'dummy verb' acting as a syntactic licenser of the direct object of the verb. Note that $b a$ occupies exactly the same head position of a higher V'-shell into which the full verb is raised in the default case. ${ }^{48}$

Contrary to the ill-formed structures $(4.18 b) /(4.19 b)$, the example (4.17) introduced in subsection 4.2 .6 is well-formed, bearing out that no verb raising takes place in this structure and that this sentence is not an instance of the AB-not pattern.

To summarize, I'd like to reiterate that the ungrammaticality of $(4.18 b) /(4.19 b)$ confirms our claim that $V^{\circ}$ raising to higher head positions of $V^{\prime}$-shells for purposes of argument licensing obligatorily takes place in A-not-A sentences, such as illustrated by means of the S-structures $\left(4.1^{\prime}\right),\left(4.2^{\prime}\right)$ and $\left(4.9^{\prime}\right)$ in section 4.2.1.

\subsection{How A-not-A and A-not questions are structured as a whole}

With respect to the problem of how A-not-A and A-not questions are structured as a whole, one of my central tenets is that they are typed in a clause-internal functional head position which I will baptize Force $2^{\circ}\left(\mathrm{F} 2^{\circ}\right)$. More importantly, this position is not identical to the head position of the functional Polarity ${ }_{1}$ Phrase (Pol1P) introduced by Drubig (1994) in order to accommodate such elements like assertive negation and elements like only or even in English.

Additionally, my subsequent claims will be based on some central tenets of Chomsky's (1995) Checking Theory. Reduced to its barest essentials, this theory involves that each functional head possesses an abstract feature $\langle\mathrm{F}\rangle$ that must be checked within its Checking Domain. This checking procedure can take place either by 'Merger', i.e. by the insertion of a lexical element before 'Spell-Out', or by 'Feature Attraction' at the level of LF.

4.4.1. As pointed out by Schaffar \& Chen (2001), A-not-A and A-not questions convey 'information focus' without exception, while ma questions are compatible not only with 'information focus' but also with 'identificational focus' (as we will see in section 7).

$47 \mathrm{Cl}$. Mei (1980: 25). According to Mei, the ba construction in this example is coming up from a place adverbial like zai bilu-li (lit. 'in the fireplace-inside' = 'in the fireplace'). This is questionable, since locative adjuncts are compatible with the A-not-A pattern (cf. Ernst (1994)).

48 In Gasde (1998), I have expounded that not only the element ba but also gei preceding the indirect object and the element bei in passive sentences may serve as dummy verbs licensing an argument of the verb. Originally, $b a$ was a verb meaning 'grasp' or 'hold'. As for its role in Modern Chinese, $b a$ is often regarded as pure marker of the direct object or as a case marker. Cf. Zou (1993), for example. 
Information focus is a type of focus which is often called presentational focus, wide focus, projective focus, maximally projected focus, novelty focus, or VP-focus. There is a general agreement that information focus has a "strictly incremental effect on the discourse" (Drubig 1998: 7) insofar as it specifies "new information". Along the lines of Kiss (1998), this type of focus conveys "non-presupposed" information marked by one or more pitch accents. In terms of Drubig (1998: 1), information focus is "licensed by integration into wider focus domains", which means that the focus feature is projected from a focus exponent. Based on this, Drubig \& Schaffar (2001: 2) claim that licensing by embedding is a default mechanism which does not entail any further expenditure of encoding. According to López \& Villalba (2000: 5), non-contrastive focus is always unmarked, i.e. no syntactic operations or morphological markers are associated with it. Seen in this light, assertive negation and English elements like only or even which may appear in Pol $1^{\circ}$ do not necessarily serve as "licensers" of information focus, as originally claimed by Drubig (1994: 22f.). Rather, they act as additional indicators of it. Whereas Drubig (1994) had declarative sentences in mind, Schaffar \& Chen (2001: 857f.) establish a relationship between A-not-A predicates and Drubig's Pol1P. More precisely, they advocate that in A-not-A questions Pol $1^{\circ}$ is occupied by some kind of question operator. This is much to their credit. Yet, strictly speaking, Schaffar and Chen do not clearly distinguish between the morphological V-not-V form of the verb and an abstract question feature in $\mathrm{Pol}^{\circ}$. Instead, they suppose to "analyze the V-neg-V form as a question operator in Poll" (p. 857). In consequence, they provide a sentence model according to which $\mathrm{Pol}^{\circ}$ can be alternatively occupied by 0 (affirmation), bu/mei (assertive negation), zhi ('only') and V-bu/mei-V (yes/no question). As an unavoidable result of this, VP remains literally empty in Schaffar \& Chen's (2001: 858) sentence model (33). ${ }^{49}$

Deviating from Schaffar and Chen's intuitively very plausible approach, whose central idea is that the question operator in A-not-A sentences is located in Pol $1^{\circ}$, I will take the position that the declarative/interrogative distinction and the affirmative/negative distinction denote different syntactic and conceptual levels which should not be mixed up. This view is empirically supported by the fact that affirmative and negative elements occur in both declarative and interrogative sentences (cf. section 5.2.5).

4.4.2. Starting from this point of view, I will claim that yes/no questions with ma on the one hand and A-not-A and A-not questions on the other are typed in two distinct positions.

Yes/no questions with the question particle ma like

(4.20) Ni nazou-le zhe ben shu ma?

you take away-ASP this $\mathrm{Cl}$ book $\mathrm{QP}$

'Have you taken away this book?'

are typed in Force $1^{\circ}\left(\mathrm{F}^{\circ}\right)$. Although located at the rightmost periphery of the sentence, $\mathrm{F} 1^{\circ}$ is a hierarchical position, from which $m a \mathrm{c}$-commands the rest of the sentence:

49 Besides, this model incorrectly gives the impression that the A-not-A form of the verb can co-occur with the sentence-final question particle $m a$ in the same clause. Referring to Laka (1994), N. Zhang (1997: 126) claims that the functional head $\Sigma$, which apparently coincides with Drubig's (1994) Pol1 ${ }^{\circ}$, can be either interrogative or negative. This claim comes close to Schaffar and Chen's (2001) approach. 


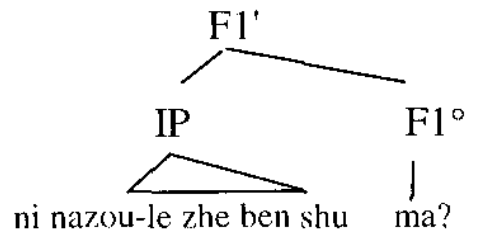

Differently from ma questions, the typing procedure of A-not-A and A-not questions happens in a clause-internal position, namely in the head position of a functional phrase which I will call 'Force2P' (F2P). ${ }^{50}$

This means that simple yes/no questions like (4.21) and (4.22) have Logical Forms like (4.21') and (4.22'), respectively:

(4.21) Ni qu-bu-qu?

you go-not-go

'Do you go there?'

$\left(4.21^{\prime}\right)\left[\mathrm{IP}_{\mathrm{P}} \mathrm{ni}_{1}\left[\mathrm{~F}_{2 \mathrm{P}}\left[\mathrm{F}^{\circ} \quad[[+\mathrm{Q}]<\mathrm{Q}>]\right]\left[\mathrm{v}^{\prime} \mathrm{t}_{1}\left[\mathrm{v}^{\prime}\left[\mathrm{v}^{\circ}\left[[\mathrm{qu}-\mathrm{bu}-\mathrm{qu}]_{[+\mathrm{Q}]}\right]\right]\right]\right]\right]\right]$ (LF)

(4.22) Ni qu-bu?

you go-not

'Do you go there?'

(4.22) [IP $\left.\left._{\text {Pi, }}\left[\mathrm{F}_{2} \mathrm{P}\left[\mathrm{F}^{\circ}{ }^{\circ}[+\mathrm{Q}]<\mathrm{Q}>\right]\right]\left[\mathrm{v}^{\prime} \mathrm{t}_{1}\left[\mathrm{v}^{\prime}\left[\mathrm{v}^{\prime}\left[[\mathrm{qu}-\mathrm{bu}]_{[+\mathrm{Q}]}\right]\right]\right]\right]\right]\right]$

That is to say, the morphological words $q u$-bu-qu 'go-not-go' and $q u$-bu 'go-not' bearing a yes/no question feature $[+\mathrm{Q}]^{51}$ are base-generated in the sentence position $\mathrm{V}^{\circ}$. At the level of LF, however, [+Q] "starts up on its own", moving to F2 ${ }^{\circ 52}$, where it is "sister adjoined" 53 to a correlating weak question feature, $\langle Q\rangle$, in order to check it.

Provided this, my contention is that it is the $<Q>$ feature checked by [+Q] that contributes interrogative force to the whole sentence in A-not-A and A-not questions. In other words, I claim that in A-not-A and A-not questions the syntactic procedure of 'clausal typing' (Cheng (1991)) takes place within the extended predicate, comprising F2P and $V^{\prime} \cdot{ }^{54}$ Moreover, I contend that yes/no questions of this type do not contain a Forcel Phrase (F1P), since one clause cannot be typed twice.

50 Note that $\mathrm{Fl}$ ' and $\mathrm{F} 2 \mathrm{P}$ are in complementary distribution.

51 Actually, [+Q] is an abbreviation of the more complex question feature [+Q, -Wh], which is one specification of the abstract clausal typing feature $[+/-Q,+/-W h]$. It ensues that Wh-questions have the feature specification $[-\mathrm{Q},+\mathrm{Wh}]$, while declaratives are marked by $[-\mathrm{Q},-\mathrm{Wh}]$.

52 Recall that 'Attraction' involves movement of a set of grammatical features carried by a head on their own (without movement of the corresponding phonetic leatures). See Radford (1997), p. 230.

53 The notion of 'sister adjunction' stems from the GB theory. To 'sister adjoin' one constituent A to another constituent $B$ is to attach $A$ under the node $C$ immediatcly dominating $B$. Opposed to this, to 'Chomsky-adjoin' A to B means to create a new B-node which immediately dominates both A and B. Cf. Radford (1981: 169).

54 Arguably, the extended predicate of A-not-A and A-not questions is an instance for a 'phase' along the lines of Chomsky (1998: 20; 1999: 9). Either a verb phrase in which all theta roles are assigned, $\mathrm{vP}$, or a full clause including tense and force can be a 'phase' in Chomsky's sense. 
4.4.3. In contrast to this hypothesis, Huang (1982: 532), Li (1992: 137f.), and Ernst (1994: 258) postulate that in A-not-A questions "the A-not-A operator" (Huang) / "the A-not-A form" (Li) / "the verb bearing [+Qu]" (Ernst) ${ }^{55}$ must raise to "Comp" at LF.

Similarly, Cheng et al. (1996: 56ff.) postulate that the negation element in "Negative Particle Questions' (i.e. 'A-not' questions) must be raised to $\mathrm{C}^{\circ}$ in Mandarin Chinese which displays agreement between the aspect of the verb and the choice of the negation element, while it is base-generated in $\mathrm{C}^{\circ}$ in non-agreement dialects of Chinese.

Differently from these hypotheses, I contend that [+Q]-raising to Comp at LF in A-not$\mathrm{A}$ and A-not questions does not take place in Mandarin Chinese. Let's take a closer look at Li's and Ernst's arguments:

$\mathrm{Li}$ (1992) is concerned with indefinite wh-phrases, the distribution of which is characterized by the fact that they can only appear in polarity environments, i.e. within the scope of a negator or of a question operator. This is the case in (4.23ab) but not in (4.24):

Ta xi-bu-xihuan shenme ${ }^{56}$

he like-not-like what

'Does he like something/anything?'

b. Shei/Shenme ren xihuan ta ma?

who /what man like him QP

'Does anyone like him?'

(4.24) *Shei/Shenme ren xi-bu-xihuan ta?

who /what man like-not-like him

In (4.23a), the indefinite wh-phrase shenme 'something/anything' appearing as the direct object of the verb is licensed by the A-not-A question operator [+Q] which, in our terms, is located in $\mathrm{F} 2^{\circ}$. In a similar manner, the indefinite wh-phrase shei/shenme ren 'anyone' acting as a subject is in the scope of the question operator in 'Comp' (to use Li's phrase) in (4.23b). In contradiction to this, the subject in (4.24) lacks a licenser, with the result that the whole structure is bad.

Claiming that the A-not-A form undergoes raising at LF, Li's problem is that she cannot explain the asymmetry in grammaticality between (4.23b) and (4.24). If in (4.24) the question operator is raised to Comp at LF, the sentence should be just as grammatical as (4.23b). To put it another way, on the precondition of an LF raising of the question operator, A-not-A structures like (4.24) should behave exactly like their counterparts with $m a$, because once the question operator has been raised to Comp, it ccommands the subject.

55 More precisely, Ernst (1994: 246) following Aqvist (1965), takes [+Qu] "as representing an imperative operator which requests information of the listener". Groenendijk \& Stokhof (1997) criticize Aqvist's view which is also maintained by Vanderveken (1990). Contrary to Aqvist and Vanderveken, Groenendijk and Stokhof regard asking a question as a basic speech act.

56 Note that in this example the verb xihuan 'like' is - optionally - truncated to its first syllable $x i$, while the semi-suffix of the lexeme in question occurs in its full form. Dai (1993: 24) derives verb forms like $x i$ by a formal operation of subtraction which deletes the second syllable -huan in xihuan in inflectional morphology. Note further that Dai's derivation of the xi-bu-xihuan form deviates from that suggested by Huang (1991: 316f.). 
In view of this dilemma (which $\mathrm{Li}$ is aware of) she argues that "indefinite Wh must be licensed at S-structure" (p. 138). This arbitrary ad hoc assumption, however, amounts to saying that the syntactic level of LF, otherwise responsible for wh-Movement, Quantifier Raising and Scope Interpretation by definition, is idle in the particular case of question operator raising.

At this juncture, the question arises what the point of a movement operation without any impact would be.

Li's Problem can easily be resolved by assuming that the [+Q] operator in (4.21) remains in $\mathrm{F} 2^{\circ}$.

Ernst (1994) correctly observes that the A-not-A pattern is incompatible with some 'core adjuncts', such as epistemic elements and causal adjuncts, whereas yes/no questions ending with the question particle $m a$ are allowed to contain such adjuncts:

$$
\begin{aligned}
& \text { *Ta yiding qu-bu-qu? } \\
& \text { he definitely go-not-go }
\end{aligned}
$$

b. Ta yiding qu ma?

he definitely go QP

'Is he definitely going?'

(4.26) a.

*Ni yinwei ni-de pengyou de yaoqiu qu-bu-qu? you because your friend PART demand gou-not-gou

b. Ni yinwei ni-de pengyou de yaoqiu qu ma? you because your friend PART demand gou QP 'Do you go there because of your friend's demand?'

Ernst (1994: 245) explains the ungrammaticality of (4.25a) by means of the "Isomorphy Principle' (IsoP) ${ }^{57}$.

In fact, the asymmetry in grammaticality between A-not-A variants and the mavariants in (4.25) and (4.26) can be explained without recourse to Ernst's IsoP, provided you don't operate on the premise that the verb bearing [Qu] must be raised to Comp. Considered from a semantic viewpoint, it suffices to say that the incompatibility of epistemic modificators and causal adjuncts with the A-not-A form of the verb arises from the fact that they both must operate over propositions. Given this, (4.25a) and (4.26a) are ungrammatical, because the $[+Q]$ feature raised to $F 2^{\circ}$ at $L F$, as required by our approach, turns the predicate represented by $\mathrm{V}^{\prime}$ into a function. ${ }^{58}$

Differently, yes/no questions with $m a$ contain a strong $<\mathrm{Q}>$-feature in $\mathrm{F} 1^{\circ}$ that has scope over the whole sentence. This feature is checked by the question particle ma which is 'sister-adjoined' to $\angle \mathrm{Q}>$ by Merger. The question feature in $\mathrm{F} 1^{\circ}$ turns the

57 This principle reads: If an operator A has scope over B at SS, then A has scope over B at LF. Based on this principle Ernst claims that sentences like (4.25a) are semantically anomalous, as adverbs like yiding cannot take question operators in their scope. And, due to the IsoP, this anomaly exists not only at S-structure but also at $\mathrm{LF}$, because not only the verb bearing [+Qu] must raise to Comp at $\mathrm{LF}$, but also the epistemic operator must raise to a pre-field position in which it has scope over the question operator, just as it had at the level of S-structure, yielding an LF like the following (p. 252, (43)):

(i) yiding $2 \mathrm{qu}-[\mathrm{Qu}]_{1}\left[\mathrm{ta}_{2} \mathbf{t}_{1}\right]$

58 For the hypothesis that from a semantic viewpoint yes/no questions are functions, see Krifka (2001a: 2). 
proposition into a function as well, but in contrast to the A-not-A structures (4.25a) and (4.26a), the epistemic modificator and the causal adjunct lie within the scope of $m a$ at every syntactic level in (4.25b) and (4.26b).

4.4.4. B. Zhang (1999: 296f.) observes that indefinite objects cannot occur in A-not-AB and $\mathrm{AB}$-not-A questions, as examples like (4.27ab) show:

(4.27) a. *Nimen mai-bu-mai yi-liang xin che? (A-not-AB) you buy-not-buy one-CL new car

b. *Nimen mai yi-liang xin che bu-mai? (AB-not-A) you buy one-CL new car not-buy

Zhang does not provide an explanation for his observation. However, granted that his observation is correct, it serves as an additional piece of evidence for my claim that Anot-A questions are typed in $\mathrm{F} 2^{\circ}$.

Huang (1987: 249) stresses that it "is well known" that a numerally quantified NP is generally specific in Chinese. With respect to our examples (4.27ab) this means that the object DP yi-liang xin che 'a new car' must undergo raising across $F 2^{\circ}$ at the level of LF. Yet, exactly this is not allowed for semantic reasons, since a question operator must have scope over the quantifier at any syntactic level. In contrast to (4.27ab), this requirement is obeyed in $(4.28)$ :

(4.28) Nimen mai yi-liang xin che ma?

you buy one-CL new car QP

'Are you buying a new car?'

It should be noted that Ernst's (1994) Isomorphy Principle does not work in cases like (4.27ab). If the IsoP were operative in such cases, not only the numerally quantified NP yi-liang xin qiche 'a new car' but also the $[+\mathrm{Q}]$ operator in $\mathrm{F} 2{ }^{\circ}$ would have to be raised to "Comp" at L.F:

(4.27') a. *["Comp"[+Q] [IP yi-liang xin che [IP nimen mai-bu-mai,e] liang one-Cl new car you buy-not-buy

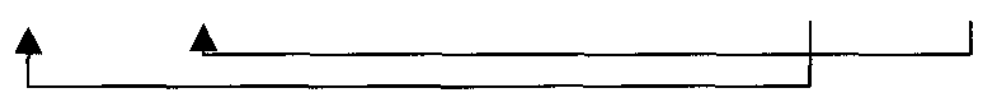

b. *["Comp" [+Q] [IP yi-liang xin che [IP nimen mai

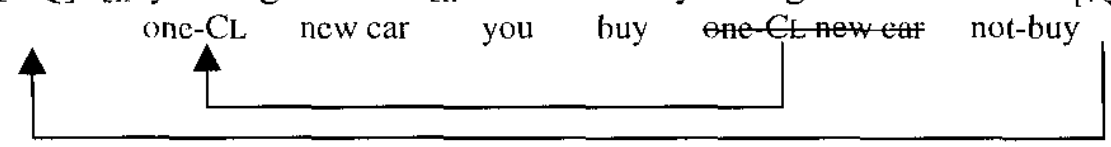

In view of this, (4.27ab) should be just as grammatical as (4.28). The fact that this is not the case proves once more that the scope of the [+Q] operator in A-not-A questions is restricted to the predicate at every syntactic level. 


\section{Yes/no questions with an overt question operator in $\mathbf{F 2}^{\circ}$}

So far we have claimed that A-not-A and A-not predicates contain an abstract [+Q] feature that checks a correlating abstract $\langle Q\rangle$ feature in $F 2^{\circ}$ by the LF operation of Attraction.

In this section, we will consider several overt question operators which are of theoretical interest insofar as they corroborate our hypothesis concerning the existence of a functional F2P. These operators with interrogative force appear both in some Chinese dialects and in Mandarin Chinese.

\subsection{Dialectal variants}

The so-called $a$-operator is used in Shanghainese and Suzhounese (both belonging to the $\mathrm{Wu}$ dialect group):

(5.1) a. Nong ming zao a dao Shanghai qu? (Xu \& Shao 1998: 89, Shanghainese) you tomorrow morning PART to Shanghai go

'Do you go to Shanghai tomorrow morning?'

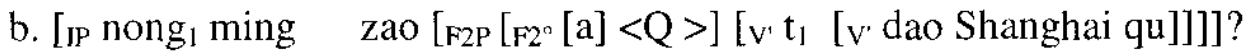
you tomorrow morning PART to Shanghai go
a. Li a kan xi?
(Yuan 1993: 103, Suzhounese)
he PART watch theatre

'Does he go to the theatre?'

b. $\left[\mathrm{IP} \mathrm{li}_{\mathrm{i}}\left[\mathrm{F}_{\mathrm{P}}\left[\mathrm{F}^{\circ}[\mathrm{a}]<\mathrm{Q}>\right]\left[\mathrm{V}^{\prime} \mathrm{t}_{1}\left[\mathrm{~V}^{\prime} \mathrm{kan} x \mathrm{xi}\right]\right]\right]\right] ?$
watch theatre

The interrogative force in (5.1) and (5.2) is exclusively conveyed by the question operator $a$ which we claim to be located in the head position of $\mathrm{F} 2 \mathrm{P}$. In $\mathrm{F} 2^{\circ}$, it is 'sisteradjoined' to an abstract $<Q>$ feature by the operation of Merge (which takes place at Dstructure). Correspondingly, the predicates of (5.1) and (5.2), dao Shanghai qu 'go to Shanghai' and kan $x i$ 'go to the theatre', respectively, can neither assume an A-not-A or A-not form nor do they contain a question feature.

The scope of the overt question operator $a$ is restricted to the predicate. Hence, just like A-not-A questions ${ }^{59}$, yes/no questions with $a$ are not consistent with epistemic elements like yiding 'definitely' or causal adjuncts like yinwei ni-de pengyou de yaoqiu 'because of your friend's demand'. And just like A-not-A questions, yes/no questions made up with the help of $a$ do not project F1', because the $a$ operator turns $V$ ' into a function.

The same should apply to the kam operator which is used in the Southern Min dialect spoken on the mainland in the province of Fujian and in Taiwan:

$$
\begin{aligned}
& \text { a. Li kam u chi:? (Huang 1991: 325) } \\
& \text { you PART have money } \\
& \text { 'Do you have money?' }
\end{aligned}
$$

5) Cf. (4.25a) and (4.26a) discussed in section 4. 


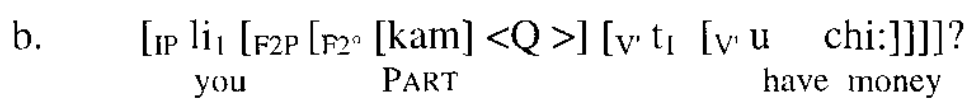

\subsection{The assertive question operator $s h i-b u$-shi in Mandarin Chinese}

In the standard variant of Mandarin Chinese, there is a type of shi-bu-shi which is not derived from the familiar "it-cleft" marker shi. Rather, it is derived from a shi which is used to "assert the proposition of a sentence", as expressed by Yeh (1995: 43).

My claim is that the A-not-A form of this 'assertion marker' is a pure question operator. ${ }^{60}$ Appearing in $\mathrm{F}^{\circ}$, assertive shi-bu-shi takes scope over the sentence constituent $\mathrm{V}^{\prime}$ which may be extended by various VP modifiers ${ }^{61}$.

5.2.1. First, consider examples like the following, in which the assertive question operator $s h i-b u-s h i$ and the full verb are adjacent to each other:

(5.4) a. Ta zuotian shi-bu-shi lai-guo? (Shao 1996: 132)

he yesterday AM-not-AM come-AsP

'Did he drop in yesterday?'

b. $\quad\left[{ }_{1 \mathrm{P}} \mathrm{ta}_{1}\right.$ zuotian $\left[\mathrm{F} 2 \mathrm{P}\left[\mathrm{F}^{\circ}\right.\right.$ [shi-bu-shi $\left.]<\mathrm{Q}>\right]\left[\mathrm{V}^{\prime} \mathrm{t}_{1}\left[\mathrm{~V}^{\prime}\right.\right.$ lai-guo $\left.\left.\left.]\right]\right]\right]$ ? he ycsterday AM-not-AM come-AsP

(5.5) a. Ni shi-bu-shi xihuan zhe ben shu?

you AM-not-AM like this $\mathrm{CL}$ book

'Do you like this book?'

b. $\quad\left[\mathrm{I}_{\mathrm{P}} \mathrm{ni}_{1}\left[\mathrm{~F} 2 \mathrm{P}_{2}\left[\mathrm{~F}_{2}{ }^{\circ}[\right.\right.\right.$ shi-bu-shi $\left.]<\mathrm{Q}>\right]\left[\mathrm{V}^{\prime} \mathrm{t}_{1}\left[\mathrm{v}^{\prime} \mathrm{xihuan}_{2}\left[\mathrm{v}^{\prime}\right.\right.\right.$ zhe ben shu $\left.\left.\left.\left.\mathrm{t}_{2}\right]\right]\right]\right]$ ? you AM-not-AM like this $\mathrm{CL}$ book

(5.6) a. Ni shi-bu-shi gaosu-le ta zhe ge xiaoxi?

you AM-not-AM tell-ASP he this CL news

'Did you tell him this piece of news?'

b. $\quad \mathrm{Ni}_{1}\left[\mathrm{~F}_{2 \mathrm{P}}\left[\mathrm{F}^{\circ}{ }^{\circ}[\right.\right.$ shi-bu-shi $\left.]<\mathrm{Q}>\right]\left[\mathrm{v}^{\prime} \mathrm{t}_{1}\left[\mathrm{v}^{\prime}\right.\right.$ gaosu-le $2\left[\mathrm{v}^{\prime}\right.$ ta $\left[\mathrm{v}^{\prime}\left[\mathrm{v}^{\circ} \mathrm{t}_{2}^{\prime}\right.\right.$

you AM-not-AM $\quad$ tell-ASP he
$\left[v^{\prime}\right.$ zhe ge xiaoxi $\left.\left.\left.\left.\left.\left.t_{2}\right]\right]\right]\right]\right]\right] ?^{62}$
this CL news

As Yeh observes, the negative counterpart of the "it-cleft" marker shi is bu-shi, while the negative counterpart of the assertion marker shi is bu or mei(you), depending on the aspect of the verb. Given this, the fact that the shi-bu-shi in (5.4) through (5.6) represents the A-not-A form of the assertion marker shi is borne out by the fact that the correct negative response to them is meiyou for (5.4) and (5.6), while it is bu for (5.5). Based on this, we can say that the predicates of our examples convey information focus.

6) Along these lincs, this type of shi-bu-shi is rendered as AM-not-AM in the subsequent examples.

${ }_{61}$ Note that, in terms of our sentence model (1.1), VP modifiers are in fact V' modifiers. Regardless of this fact, we use the more familiar notion 'VP modifier' in the subsequent text.

(2) $\mathrm{Cf}$. the abstract sentence structure given in section 3 under (3.2). 
5.2.2. Differently from the examples above, the shi-bu-shi operator in (5.7) and (5.8) is adjacent not to the full verb of the sentence but to a dummy verb. In (5.7), it is adjacent to the dummy verb $b a$ treated in section 4 :

(5.7) a. Zhang San shi-bu-shi ba zhe ben shu kanwan-le?

Zhang San AM-not-AM BA this $\mathrm{Cl}$ book finish-AsP

'Has Zhang San finished this book?'

b. Zhang $\operatorname{San}_{i}\left[{ }_{F 2 P}\left[F_{2}{ }^{\circ}[\right.\right.$ shi-bu-shi $\left.]<Q>\right]\left[\mathrm{V}^{\prime} \mathrm{t}_{1}\left[\mathrm{~V}^{\prime}\right.\right.$ ba $\left[\mathrm{v}^{\prime}\right.$ zhe ben shu

Zhang San AM-not-AM BA this $\mathrm{Cl}$ book
kanwan-le ]]]]?
finish-ASP

Drubig \& Schaffar (2001: 4) consider the $b a$ construction as a mechanism to remove defocused arguments from the focus domain. Given this pragmatic approach, the shi-bushi operator in (5.7) is obligatorily assertive.

In the same manner, the shi-bu-shi operator is assertive in the following example, where the dummy verb ge $i$ serves as a syntactic licenser of the indirect object:

(5.8) a. Ni shi-bu-shi gei Li Si ji-le yi-ben shu? you AM-not-AM to $\mathrm{Li} \mathrm{Si}$ send-ASP one-CL book 'Have you sent a book to $\mathrm{Li} \mathrm{Si}$ ?'

b. $\quad \mathrm{Ni}_{1}\left[\mathrm{~F}_{2} \mathrm{P}\left[\mathrm{F}_{2^{\circ}}[\right.\right.$ shi-bu-shi $\left.]<\mathrm{Q}>\right]\left[\mathrm{v}^{\prime} \mathrm{t}_{1}\left[\mathrm{~V}^{\prime}\right.\right.$ gei $\left[\mathrm{v}^{\prime} \mathrm{Li}\right.$ Si $\left[\mathrm{v}^{\prime} \mathrm{ji}-\mathrm{le}_{2}\left[\mathrm{~V}^{\prime}\right.\right.$ yi-ben you AM-not-AM to Li Si send-ASP one-CL
shu $\left.\left.\left.\left.\left.\left.\mathrm{t}_{2}\right]\right]\right]\right]\right]\right]$ ?
book

According to Yeh's negation test, (5.7) and (5.8) contain the assertive question operator shi-bu-shi, for in both cases the correct negative response is mei you.

5.2.3. Now consider some examples in which the assertive shi-bu-shi operator is adjacent to a VP modifier:

(5.9) a. Ni shi-bu-shi zai Beijing mai-le bu-shao dongxi?

you AM-not-AM in Beijing buy-AsP not-little thing

'Did you buy a lot of things in Beijing?'

b. $\mathrm{Ni}\left[\mathrm{F} 2 \mathrm{P}\left[\mathrm{F}^{\circ}{ }^{\circ}\right.\right.$ shi-bu-shi $]\left[\mathrm{v}^{\prime}\right.$ zai Beijing $\left[\mathrm{v}^{\prime}\right.$ mai-le $\mathrm{e}_{\mathrm{i}}\left[\mathrm{v}^{\prime}\right.$ bu-shao dongxi $\left.\left.\left.\left.\mathrm{t}_{\mathrm{i}}\right]\right]\right]\right]$ ?
you AM-not-AM in Beijing buy-AsP not-little thing

The ability of the assertive question operator shi-bu-shi to appear in the above structure can be accounted for along these lines of Speas (1990: 49ff.) who rejects the hypothesis of Lebeaux (1988) that D-structure includes heads and arguments and nothing else. That is to say, she rejects the allegation that all adjuncts are added to the phrase marker AFTER D-structure. To give evidence for her position, Speas shows by means of English examples, which hold true for Chinese as well, that benefactive, locative and instrumental PPs "do not show anti-reconstruction effects".

As for benefactives, compare the strong crossover cases $(5.10 a, b)$ which convincingly prove that these phrases must be present at D-structure: 
(5.10) a. *For Mary 's brother, she ${ }_{1}$ was given some old clothes.

b. $\quad$ Weile Zhang $\operatorname{San}_{1}$ de anquan, ta $a_{1}$ duobi-zai cheng-li.

for Zhang San PART safely he hide-in town-inside

*'For Zhang San,'s safety, he ${ }_{1}$ was hiding in the town.'

In contrast to $(5.10)$, weak crossover configurations like in (5.11) are well-formed:

(5.11) Zhang $\operatorname{San}_{1}$ shi-bu-shi weile tą-de anquan duobi-zai cheng-li?

Zhang San AM-not-AM for his safety hide-in town-inside

'Does Zhang San hide in the town for his safety?'

Given Speas' theory, it seems justified to regard locatives and benefactives as a part of the extended predicate.

Chinese behaves like English and other languages in that "focus has a systematic phonological manifestation in the form of (sentence/pitch) accent" ${ }^{13}$. This implies that the shi-bu-shi operator in (5.9) and (5.11) is assertive on the condition that the VP modifier following it does not carry the pitch accent of the sentence. If the modifier does carry the pitch accent, the shi-bu-shi operator preceding it cannot be assertive and the predicate lying in the scope of this operator cannot not convey information focus. Instead, it conveys identificational focus, as we will see in section 7.

5.2.4. The predicate in the scope of assertive shi-bu-shi can consist of a matrix clause and a complement clause. In that case, the assertive question operator occupies the $F 2^{\circ}$ position of the matrix clause:

(5.12) Zhang San shi-bu-shi yunxu Li Si he pijiu?

Zhang San AM-not-AM allow Li Si drink beer

'Has Zhang San allowed Li Si to drink beer?'

The information focus conveyed by (5.12) may comprise either the matrix predicate representing a control structure in which the object of the matrix verb controls the PRO subject of the complement clause, as in $\left(5.12^{\prime}\right)$, or merely the predicate of the embedded clause, as in (5.12"): ${ }^{64}$

(5.12') Zhang San [F2P shi-bu-shi [ $\mathrm{V}^{\prime}$ F $\left[y u n x u \mathrm{Li} \mathrm{Si}_{i}\left[\mathrm{PRO}_{\mathrm{i}}\right.\right.$ he pijiu]]]]

Zhang San AM-not-AM allow $\mathrm{Li} \mathrm{Si}$ drink beer

(5.12") Zhang San [F2P shi-bu-shi [v' yunxu Li Si ${ }_{i}\left[\mathrm{PRO}_{\mathrm{i}}[\right.$ he pijiu]]]

Zhang San AM-not-AM allow $\mathrm{Li} \mathrm{Si}$ drink beer

63 Cl. Rochemont \& Culicover (1990: 17).

64 Note that the shi-bu-shi operator cannot appear in the cmbedded clause:

(i) *Zhang San yunxu Li Si shi-bu-shi he pijiu?

That is, the opcrator concerned must have scope over the matrix predicate, even if only the embedded predicate is 'new information'. Von Stechow (1991: 810 (45)) and Drubig (1994: 20ff.) discuss the problem with the help of English focus-sensitive particles like only and others which can be ambiguous with respect to focus. See also Taglicht (1984). 
5.2.5. The shi-bu-shi operator is obligatorily assertive if it is followed by a modal, a negation, or a negation combined with a modal, as observed by Liu \& Pan \& Gu (1983: 491ff.):

(5.13) a. Dasuan shi-bu-shi neng sha xijun?

garlic AM-not-AM able kill germ

'Is garlic able to kill germs?'

b. Ni shi-bu-shi bu tongyi zhe zhong yijian?

you AM-not-AM not agree this kind opinion

'Do you not agree with this kind of opinion?'

c. Zhe zhong shi, shi-bu-shi bu gai zuo?

this kind matter AM-not-AM not ought do

'As for this kind of matters, should one do them?'

The fact that the assertive question operator shi-bu-shi is consistent with a sentence negation, as $(5.13 \mathrm{~b}, \mathrm{c})$ show, is highly significant, since it vindicates our hypothesis set up in section 4.4 that $F 2^{\circ}$ and Drubig's (1994) Pol $1^{\circ}$ are distinct sentence positions which must be strictly distinguished from each other. Whereas $F 2^{\circ}$ acts as the host of the assertive question operator shi-bu-shi, $\mathrm{Pol}^{\circ}$ (or, in terms of Drubig, Poll ${ }^{\circ}$ ) is the head position which sentence negations appear in.

The phenomenon that yes/no questions with the assertive question operator shi-bushi are consistent with a V'-external negator while A-not-A and A-not sentences are not results from the fact that the negative element within the A-not-A form of the verb "is just as real as the one in disjunctive questions" $" 65$. In contrast, the predicates in cases like $(5.13 \mathrm{~b}, \mathrm{c})$ above lack any negator incorporated into the verb form.

Notice that the $b u$ element in the shi-bu-shi operator is not aspect-sensitive. This is an easily verifiable statement: assertive $s h i-b u-s h i$ is compatible with perfective predicates, as the example (5.9) given under 5.2.3 shows. Even in this sentence, the bu element incorporated into the shi-bu-shi operator cannot be replaced with mei you (a shimeiyou-shi operator does not exist in Chinese). In short, assertive shi-bu-shi is a pure question operator whose internal $b u$ element does not negate the predicate of the sentence.

5.2.6. Our claim that the shi-bu-shi described in this section is an assertive question operator which conveys information focus can be confirmed by two tests:

First, sentences containing this type of $s h i-b u$-shi are incompatible with Ernst's 'core adjuncts', just as A-not-A and A-not questions are ${ }^{66}$ :

(5.14) Ta (*yiding) zuotian (*yiding) shi-bu-shi lai-guo?

he definitely yesterday definitely AM-not-AM come-AsP

'Was he already here (once) yesterday?'

(5.15) $\mathrm{Ni}$ (*yinwei zhe ge guanxi) shi-bu-shi xihuan zhe ben shu? you for this CL reason AM-not-AM like this $\mathrm{CL}$ book

\footnotetext{
65 McCawley 1994, p. 181.

60 In contrast to this, the "it-cleft" question operator shi-bu-shi is compatible with 'corc adjuncts'.
} 
Second, sentences containing this type of shi-bu-shi allow continuations like (5.16A):

Q: Zai zuotian-de hui-shang, ni shi-bu-shi tongyi-le ta-de yijian? at yesterday-PART meeting-above you AM-not-AM agree-AsP his opinion 'Did you agree with his opinion at yesterday's meeting?'

A: Dui, erqie ni-de yijian wo qishi ye tongyi-le. Correct, and your opinion I basically also agree-Asp 'Correct, and as for your opinion, I basically also agreed.'

Answers like that in (5.16) are pragmatically appropriate, if the entity concerned ('his opinion' in (5.16Q)) permits alternatives (such as 'your opinion'). Phrased differently, 'his opinion' in (5.16Q) is not exhaustively used. This fact is relevant in that exhaustivity is a significant feature of identificational focus which I will take care of in section 7.

5.2.7. To summarize briefly, the occurrence of overt clause-internal question operators confirms our claim about the existence of a functional F2P other than Pol1P. Furthermore, it bears out our assumption made in section 4 that there is an abstract $<Q>$ feature in $\mathrm{F} 2^{\circ}$ which has to be checked by an abstract [+Q] feature in the case of A-not-A and A-not predicates. This checking procedure takes place at $\mathrm{LF}$, while the checking of $\langle\mathrm{Q}>$ by the assertive operator $s h i-b u$-shi happens by merging the question operator with $<Q>$ at D-structure.

\section{Topics in yes/no questions}

At first glance, the question of the role topics play in yes/no questions seems easy to answer, because semantically there is no reason why, instead of making a comment, the speaker cannot ask a question about the topic, as Huang (1981/82: 397) pointed out. But looking at it again, issues like an appropriate typology of topics, problems like whether different kinds of topics are anchored to different syntactic positions, the syntactic status of contrastive topics, and others are quite intricate.

\subsection{Two basic types of topic}

Semantically, there are two basic types of topics which should be strictly distinguished from each other: Frame-Setting Topics (FST) and Aboutness Topics (AT).

FSTs set an individual (entity-related), spatial, temporal or conditional frame within which the main predication holds, i.e. they do not make any direct contribution to the descriptive content of an assertion but supply information about the relevant contextual background to which the descriptive content is related. ${ }^{67}$

ATs bear a selectional relation to the verb of the sentence. They are divisible into 'outer' and 'inner' ATs. An outer AT is related to an argument position of the verb which may be occupied by a resumptive pronoun, an epithet ${ }^{68}$ or an empty element. The

67 Cf. Chafe (1976), Haiman (1978) and Maienborn (1996).

68 Cl. Lasnik \& Stowell (1991: 708): Epithets may function as non-referential bound variables, provided their antecedent is not in a c-commanding A-position. 
inner AT, however, coincides with the unmarked subject. ATs are presented as already existing in the discourse, as the item about which knowledge is added. ${ }^{69}$

Our distinction between FSTs and ATs corresponds to the observation of Yuan (2000: 3) that grammaticalized topics can be traced back to two sources: discourse topics and sentence-internal elements. Asher (1993) claims that discourse topics are propositions. Given this, it is quite natural that many FSTs in Chinese everyday speech have the form of a clause. Let's have a look at the following arbitrary examples which contain both FSTs (a-c) and ATs (d-g):

(6.1) a. Ta yaoshi fei yao zou ne, ni liu-bu-liu ta ${ }^{70}$

He if whatever happens want go PART you stop-not-stop he

'If he wants to go whatever happens, will you stop him?'

b. (Shuo-qi) shuiguo (a), ni xi-bu-xihuan pinguo?

(talking of) fruit (PART) you like-not-like apples

'While we are talking of fruits, do you like apples?'

c. Zhiyu qita wenti, nimen zuohaole-meiyou-zuohao yiqie zhunbei?

as for other issue you finish AsP $_{\text {-not-finish all preparation }}$

'As for the other issues, have you prepared anything?'

d. Yi Hangzhou bendiren shuo ba, tamen he-bu-he cha?

take Hangzhou native people speak PART they drink-not-drink tea?

'As for the native people of Hangzhou, do they drink tea?'

e. Zhe ge ren, ni xi-bu-xihuan ta / zhe ge jiahuo?

this CL man, you like-not-like he / this CL guy

'(As for) this man, do you like him / this guy?'

f. Zhe ben shu ni kan-bu-kan?

this CL book you read-not-read

'(As for) this book, will you read (it)?'

g. Li xiansheng ne, ren-bu-renshi ni?

$\mathrm{Li}$ mister PART know-not-know you

'(As for) Mr. Li, does (he) knows you?'

Based on Yuan's (2000) and Asher's (1993) conception, DPs serving as a FST like the one in $(6.1 b)$ are the remainder of truncated clausal structures. Moreover, the optional particle in $(6.1 \mathrm{~b})$ is in essence a clause-final modal particle. ${ }^{71}$

Finally, our view involves that one topic-comment structure may simultaneously comprise a FST and an AT (the subject). This applies to the examples (6.1a) through (6.1f).

(6) Cf. Gundel (1988 [1974]), Reinhart (1982), Molnár (1991) and others. Note that our notion of topic does not include "secondary topics" in the sense of Tsao (1990), Xu \& Liu (1998) and others.

70 Based on the observation that conditional clauses and topics are marked identically in a number of unrelated languages, Haiman (1978) postulated that conditionals are topics. Biq (1988), Tsao (1990) Bolland (1993), Gasde (1993), Gasde \& Paul (1996), and Xu \& Liu (1998) have applied this idea to Chinese.

71 Many researchers would interpret this particle as a "topic marker". See Xu \& Liu (1998), for example. 
This conception is consistent with Jacobs' (2001: 641) claim that "the topic can show different degrees of syntactic integration into the rest of the sentence, from full integration (the topic has a grammatical function in the main clause of the sentence) via loose integration (the topic is realized outside the clause, but coindexed with an element within the clause) to total lack of integration (the topic is neither inside the clause nor co-indexed with an element in the clause)".

\subsection{Topics as speech acts and the syntactic consequences of this postulate}

6.2.1. In this paper, I will follow Krifka (2000: 1, 5; 2001b: 11f.) who postulates that "topic selection is a speech act itself, an initiating speech act that requires a subsequent speech act, like an assertion, question, command, or curse about the entity that was selected". This view was basically also held by Lippert $(1965)^{72}$, Altmann (1981), and Jacobs (1984).

In consequence, both FSTs and ATs (except for the AT that coincides with the unmarked subject) must be base-generated in a structural position from which they ccommand the comment. This c-commanding condition is vital especially with respect to ATs, which corefer with a resumptive or empty element serving as an argument of the verb by definition.

I claim that both types of topic are adjoined to the highest functional projection of the sentence, i.e. to $\mathrm{Fl}^{\prime}$ in declaratives and $m a$ questions, as suggested in my sentence model (1.1), and to IP (as in (6.1f)) or F2P (as in 6.1g)), respectively, in A-not-A questions ${ }^{73}$. This treatment agrees with Krifka's (ibid.) claim that topics have "to scope out of speech acts".

6.2.2. Note that, according to this approach, FSTs and outer ATs do not occupy different sentence positions, as opposed to a conceivable alternative derivation of sentences like (6.1f) by movement into a prefield position, say into a TopP lying in the scope of $\mathrm{F} 1^{\circ}$. Yet this derivation, which would imply an abstract sentence structure like

$$
\mathrm{Fl} \mathrm{l}^{\prime}>\mathrm{TopP}>\mathrm{IP}>\ldots \mathrm{V}^{\prime}
$$

is disproved by weak crossover configurations like the following:

(6.3) Zhe tiao ke'ai de gou $_{l}$, tal -de zhuren xi-bu-xihuan $t_{l}$ ? this CL lovely PART dog his master like-not-like lit. 'This lovely dog, does its master like [it]?'

The structure that we have tentatively assumed for (6.3) in the above violates the Bijection Principle elaborated on by Koopman \& Sportiche (1982/83: 145f.):

(6.4) a. A variable is locally bound by one and only one element in a non-A-position.

b. Or, inversely: An element in a non-A-position locally binds one and only one variable.

\footnotetext{
72 Lippert's (1965) dissertation, though being rarely paid attention to, is ingenious in that it anticipated the greater part of what was discussed in the US in connection with the notions of 'Chinese-style' Topics and 'Topic-Prominence' by Li \& Thompson (1974; 1976), Chafe (1976) and others ten ycars later.

${ }^{73} \mathrm{Cf} .\left(6.1 f^{\prime}\right)$ and $\left(6.1 . \mathrm{g}^{\prime}\right)$ below.
} 
(6.3) violates this principle insofar as the topic locally binds a possessive pronoun ${ }^{74}$ and an empty category which is a variable according to Chomsky's GB theory ${ }^{75}$. Yet, the grammaticality of (6.3) is predicted if we start from the premise that its topic is basegenerated in its peripheral position, and if we do not consider the empty category in (6.3) as a variable trace. In terms of Lasnik \& Stowell (1991), empty elements like the one in (6.3) are "null epithets", while Rizzi (1997: 293) defines them as "null constants". Along the lines of Rizzi, a null constant is licensed by an 'anaporic operator' (OP) seeking for an antecedent, to which it connects the bindee. For (6.3), this roughly yields the following $\mathrm{S}$-structure:

(6.3') [IP [Zhe tiao ke'ai de gou $]_{1},\left[{ }_{1 P}\left[\mathrm{ta}_{1}\right.\right.$-de zhuren $]\left[\mathrm{V}^{\prime} \mathrm{OP}_{1}\left[\mathrm{~V}^{\prime} \mathrm{xi}\right.\right.$-bu-xihuan $\left.\left.\left.\left.\mathrm{e}_{1}\right]\right]\right]\right]$ ? this $\mathrm{Cl}_{\text {L }}$ lovely PART dog his master like-not-like

This analysis of (6.3) does not violate the Bijection Principle, since the topic (which is base-generated outside the comment) binds one and only one variable, namely the possessive pronoun in the subject DP (which is used as a variable), while the empty element in $V^{\prime}$ is bound and licensed by an anaphoric operator which connects the topic to the empty element.

Based on this conception, the S-structures of $(6.1 \mathrm{f}, \mathrm{g})$ given at the beginning of this section are $\left(6.1 \mathrm{f}^{\prime}\right)$ and $\left(6.1 \mathrm{~g}^{\prime}\right)$ :

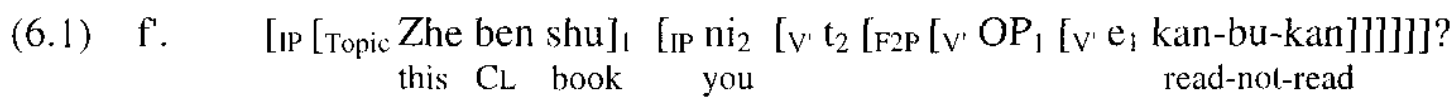

$g^{\prime} . \quad\left[\right.$ F2P $[\text { Topic Li xiansheng }]_{i}$ ne, $\left[F_{2 P}\left[v^{\prime}\right.\right.$ OP $\left[v^{\prime} e_{i}\left[v^{\prime}\right.\right.$ ren-bu-renshi ni $\left.\left.\left.\left.]\right]\right]\right]\right]$ ?

$$
\text { Li mister PART know-not-know you }
$$

An inevitable consequence of the topic theory roughly outlined above is that topicalization as a syntactic movement operation does not exist in Chinese sentences.

\subsection{Contrastive topics}

First, consider the following dialogue in a pet home, where two visitors are discussing the loveliness of some dogs:

Q: (Name) ZHE tiao gou ni XI-BU-XIHUAN?

but this $\mathrm{CL}_{\mathrm{L}}$ dog you like-not-like

'But (as for) THIS dog, do you like (it)?'

A1: Dui, erqie NA tiao gou wo ye xihuan.

correct and that $\mathrm{CL} \operatorname{dog} \mathrm{I}$ also like

'Correct, and (as for) THAT dog, I like (it) as well.'

\footnotetext{
74 Cf. Koopman \& Sportiche (1982/1983): If a pronoun is locally non-A-bound, it is no longer a pronoun; instead, it acts as a variable.

75 See Chomsky (1982), p. 330.
} 
A2: $\mathrm{Bu}, \mathrm{ZHE}$ tiao gou wo BU xihuan. no this $\mathrm{CL} \operatorname{dog} \mathrm{I}$ not like lit. 'No, THIS dog, I do NOT like (it).'

A3: \#Bu shi, wo shi xihuan na tiao gou. ${ }^{76}$ not right I sHI like that $\mathrm{CL}$ dog 'Wrong, it's that dog that I like.'

The question (6.5Q) put by one of the interlocutors contains a contrastive topic par excellence.

Phonologically, the question contains two pitch accents, the first one of which marks the topic as contrastive, whereas the second one marks the predicate as conveying information focus.

According to Molnár (1998: 133), contrastive topics and "operator focus" share the feature of "exclusion", i.e. they have the feature [+exclusive], as opposed to information focus which has the feature [-exclusive]. Yet, as Molnár underlines, contrastive topics lack the feature of "exhaustivity" which is a distinctive characteristic of 'operator focus' (in our terminology: identificational focus, see below, section 7) .

This ambiguous position of contrastive topics between non-operator focus and operator focus is the reason why they have been baptized "focus topics" by Ernst \& Wang (1995: 239), "topic focus" (huati jiaodian) by Xu \& Liu (1998: 228), and "narrow focus" by Schaffar \& Chen (2001: 841ff.). Investigating the distinct syntactic behavior of "thematic topics" (TT) and "contrastive topics" (CT) in Korean, Cho (1997: 44) points out that the "apparent distributional difference between TT and CT has been one of the important reasons to posit a new primitive, that is CT, in the grammar".

As far as our example (6.5) is concerned, Molnár's argument that contrastive topics are not exhaustive is proved by the pragmatic appropriateness of the answer A1. As we will see in section 7, the inappropriateness of A3 shows that the sentence-initial DP in (6.5Q) is no identificational focus.

Last but not least, our claim that this DP is a contrastive topic is validated by the fact that the predicate appears in the A-not-A form. Identificational focus is incompatible with the A-not-A form of the predicate.

\subsection{Can Frame-Setting Topics be cleft?}

In the following, I will claim that in Chinese not only outer ATs but also FSTs cannot be cleft, though in the case of locative and temporal FSTs quite the opposite seems to be the case.

6.4.1. Topics can be contrastively used, as depicted in the preceding section. This is not surprising in view of the fact that not only complex syntactic units but also words and even singular syllables of a word can be contrastively used in corresponding contexts.

Yet, topics cannot be preceded by the "it-cleft" marker shi. This has been noted by Chiu (1993: 126, 134), giving only the following example for her contention:

76 Note that I use small capitals to indicate the location of pitch accents within information focus, and bold type to mark identificational focus. 
(6.6) *shi neiben shu, Akiu zuotian mai-de.

SHI that book, Akiu yesterday buy-DE

Referring to Chiu, Paris (1995: 154; 1998: 152) puts it in the words that "a topic cannot be cleft". Basically, what Chiu and Paris have in mind are 'outer ATs'.

If their claim is correct, yes/no questions with non-assertive $s h i-b u$-shi $i^{77}$ preceding a topic as in (6.7) must be ungrammatical as well:

(6.7) *Shi-bu-shi zhe tiao gou ni xihuan? SHI-BU-SHI this $\mathrm{CL}$ dog you like

6.4.2. On the face of it, there seem to exist several counterexamples to Chiu's claim. For example, let's consider the following one:

Q: Shi-bu-shi ZHE ge ren ni feichang TAOYAN?

SHI-BU-SHI this CL man you very dislike

Against all appearances, $(6.8 \mathrm{Q})$ does not contain a "cleft" topic, but rather a topic that is just as contrastive as that in (6.5) above. In fact, (6.8Q) as a whole is a "verum question', where the information focus is extended over the whole sentence by definition. ${ }^{78}$ Hence, the meaning of (6.8Q) comes close to

(6.8Q') lit. 'Could it be the case that THIS GUY, you very DISLIKE (him)?'.

Accordingly, an appropriate rejoinder to $(6.8 \mathrm{Q})$ could be $(6.8 \mathrm{Al})$ or $(6.8 \mathrm{~A} 2)$, while (6.8A 3$)$ is pragmatically inappropriate:

(6.8) A1: Dui, erqie NA ge ren, wo ye bu xihuan. correct, and that CL dog I also not like

'Correct, and (as for) that man I don't like (him) either.'

A2: $\mathrm{Bu}, \mathrm{ZHE}$ tiao goll wo BU xihuan.

no this $\mathrm{CL} \operatorname{dog} \mathrm{I}$ not like

'No, this dog, I don't like (it)'

A3: \#Bu-shi. Wo shi taoyan na ge ren.

not right I SHI dislike that CL man

'Wrong. It is that man that I dislike.'

$\mathrm{A} 4:{ }^{*} \mathrm{Bu}$, shi na tiao gou wo xihuan.

no shi that $\mathrm{CL} \operatorname{dog} \mathrm{I}$ like

The appropriateness of Al shows that the sentence-initial DP zhe ge ren 'this guy' must be a contrastive topic, since it lacks the feature of exhaustivity. The difference in the pragmatic appropriateness between $\mathrm{A} 2$ and $\mathrm{A} 3$ displays that contrastive topics are

77 The nature of this complex focus and question marker will be examined in detail in section 7.

78 As for the notion of 'verum focus', cf. Höhle (1992). See also Kiss (1998: 264). The notion of 'vcrum question' has been introduced into the relevant literature by Chen \& Schaffar (1997: 15f.), as far as I know. 
compatible with the idea of negation, but incompatible with the idea of correction ${ }^{79}$. Finally, an answer like A4 is not only pragmatically inappropriate but also grammatically excluded by Chiu's claim that topics cannot be preceded by shi.

Another kind of apparent counterexamples concerns cases in which a sentence-initial locative or temporal expression is preceded by shi-bu-shi. First, consider the following case which is apparently well-formed:

(6.9) Shi-bu-shi zai Beijing Daxue, jiuhu suoyou-de liuxuesheng dou gei ni SHI-BU-SHI at Beijing University almost all the-SUFF foreign students all toward you liuxia-le shenke-de yinxiang? make-ASP deep-SUFF impression

Arguing with Tang (1983), Paris (1995: 154ff.; 1998: 152ff.) points out that the agrammaticality of some clefts is not due to the topicality of the sentence-initial constituent that is preceded by shi. Instead, she claims, their agrammaticality can be traced back to the distinction between stage-level predicates (SLPs) and individual-level predicates (LIPs).

This claim is consistent with the theoretical framework of Kratzer (1988; 1995: 126ff.) who posits that some uses of spatial and temporal expressions are sensitive to the distinction between SLPs and LIPs. Both types of predication differ in their argument structure. SLPs have an extra argument position for spatiotemporal locations, while ILPs lack this position.

Leaving certain details aside, this means that both types of predication are compatible with locative and temporal Frame-Setting Topics, but ILPs (statives) are defective in that they are incompatible with locative and temporal VP modifiers, i.e. with locative and temporal expressions narrowly modifying only the VP of the sentence.

In this connection, compare the following two declaratives, which differ insofar as (6.10) contains a SLP while (6.11) includes an ILP:

(6.10) Zai Beijing Daxue, jiuhu suoyou-de liuxuesheng dou gei wo at Beijing University almost all the-SUFf foreign students all toward I liuxia-le shenke-de yinxiang. make-AsP deep-SUFF impression
a. 'Almost all of the foreign students at Beijing University made a deep impression on me.'
b. 'Almost all the foreign students made a deep impression on me at Beijing University.'

(6.11) Zai zhe ge cunzi-li, jihu suoyou-de jumin dou shi nü-de. in this $C_{L}$ village-inside almost all the-SUFF inhabitants all be femalc-SUFF 'Almost all the inhabitants of this village are female.'

In terms of Kratzer, the 'a.'-reading of (6.10) and the reading of (6.11) indicate that the spatial expression involved modifies the restricting predicate of the quantifier 'almost all', whereas the 'b.'-reading of (6.10) signals the spatial expression to modify the main predicate of the sentence.

\footnotetext{
79 Cf, Lambrecht (1994), p. 291.
} 
In our terms, this means that the 'a.'-reading of (6.10) and the reading of (6.11) denote that the locative expressions concerned act as FSTs, whereas the 'b.'-reading of (6.10) denotes that the locative expression acts as VP modifier.

Based on this, consider the yes/no question (6.9) again. This sentence is ill-formed with the reading $\left(6.9^{\prime} \mathrm{a}\right)$ but well-formed with the reading $\left(6.9^{\prime} \mathrm{b}\right)$ :

$(6.9$ ') a. lit. *'Was it almost all of the foreign students at Beijing University that made a deep impression on you?'

b. lit. 'Was it at Beijing University where almost all of the foreign students made a deep impression on you?'

In the 'a.'-reading of (6.9), the sentence-initial locative expression serves as a FST, while it acts as a VP modifier in the 'b.'-reading of this sentence. Accordingly, the former reading is ruled out (because a topic cannot be cleft), whereas the latter reading with the locative expression acting as a VP modifier is permitted, because VP modifiers can be cleft.

The 'b.'-reading of (6.9) corresponds to the reading of example (6.12) in which the VP modifier occupies a clause-internal position:

(6.12) Jihu suoyou-de liuxuesheng shi-bu-shi dou zai Beijing Daxue gei ni almost all the-SUFF foreign students SHI-BU-SHI all at Beijing University toward you liuxia-le shenke-de yinxiang?

makc-AsP deep-suFF impression

lit. 'Was it at Beijing University where almost all of the foreign students made a deep impression on you?'

To summarize, the yes/no question sentence (6.9) is well-formed, but is has a VP modifier reading. Ergo: (6.9) is no real counterexample to Chiu's claim that topics cannot be cleft.

Now, look at the question form (6.13) of the declarative (6.11) introduced above. (6.13) differs from (6.11) in that the locative FST contained in it is "cleft" by the non-assertive focus and question operator shi-bu-shi:

(6.13) *Shi-bu-shi zai zhe ge cunzi-li, jihu suoyou-de jumin dou shi nü-de? SHI-BU-SHI in this CL village-inside almost all the-SUFF inhabitants all be female-SuFF

This sentence is absolutely ruled out, because the ILP in it lacks a 'b.'-reading. This fact is borne out by the agrammaticality of (6.14), a structure in which the locative expression zai zhe ge cunzi-li 'in this village' directly precedes the predicate:

(6.14) ${ }^{*}$ Jihu suoyou-de jumin dou zai zhe ge cunzi-li shi nü-de ma? almost all the-SUFF inhabitants all in this $\mathrm{CL}$ village-inside be female-SUFF QP

As stated above, LPs lack an extra argument position for spatiotemporal locations.

Along the lines of Kratzer's framework, not only spatial but also temporal expressions are sensitive to the type of predication they co-occur with. Compare (6.15) below containing a SLP with example (6.16) whose predicate represents an ILP: 
(6.15) Shi-bu-shi shang-ge xingqi, jihu suoyou-de SHI-BU-SHI last-CL week almost all the-SUFF shenke-suFf yinxiang?

deep-suFF impression

a. lit. *'Was it almost all last week's applicants that made a deep impression on you?'

(conceivable reply: This week's applicants were not as good.)

b. lit. 'Was it last week that almost all the applicants made a deep impression on you?'

(conceivable reply: The applicants were not as good this week.)

(6.16) *Shi-bu-shi shang-ge xingqi, jihu suoyou-de shenqingren dou shi nan-de? SHI-BU-SHI last-CL week almost all the-SUFF applicant all be male-SUFF

Whereas the temporal expression 'last week' in (6.15) has a VP modifier reading that is consistent with the idea of clefting, the same expression lacks such a reading in (6.16). Correspondingly, a sentence with the temporal expression appearing clause-internally is grammatical in the case of (6.17), but ungrammatical in a case like (6.18):

(6.17) Jihu suyou-de shenqingren Shi-bu-shi shang-ge xingqi dou gei ni liuxia-le almost all the-SUFF applicant SHI-BU-SHI last-CL week all toward you make-ASP shenke-de yinxiang? deep-SUFF impression 'Was it last week that almost all the applicants made a deep impression on you?'

(6.18) *Jihu suoyou-de shenqingren shang-ge xingqi dou shi nan-de. almost all the-SUFF applicant last-CL week all be male-SUFF

Our examples show that temporal FSTs cannot be cleft, just like locative ones.

6.4.3. In fact, Chiu's claim that topics are excluded from clefting is correct not only for empirical but also for theoretical reasons.

If a topic shall be cleft, it must be marked by the "it-cleft" marker shi or by the complex focus and question marker shi-bu-shi. Whereas shi assigns the phrase with which it is associated a focus feature, shi-bu-shi assigns a focus and a question feature.

According to the checking theory, both features have to check a correlating feature in the head position of specific functional phrases, as we will see in section 7 . Yet, such head positions are not available to topics. For, as separate speech acts, topics are located outside the scope of $\mathrm{F} 1^{\prime}$ and FocP, as indicated in our sentence model (1.1), and so neither their focus nor their question feature can be discharged, if they are associated with shi or shi-bu-shi.

For empirical and theoretical reasons, FSTs and sentence-initial VP modifiers cannot occupy the same sentence position. Applied to (6.10), this means that the FST in (6.10a) is adjoined to FI' while the VP modifier in $(6.10 \mathrm{~b})$ is adjoined to IP. Although intonationally separated from the rest of the sentence, the latter is not a separate speech act. 


\section{Identificational focus in yes/no questions}

In the previous sections, we have dealt with the role of information focus in Chinese yes/no questions. We have learned that not only A-not-A and A-not questions but also questions containing assertive shi or shi-bu-shi are tied to that type of focus, only relevant on the pragmatic level by specifying "context-incrementing (or 'new') information" $" 80$. In the terminology of Kiss (1998: 246), information focus conveys "non-presupposed information marked by one or more pitch accents".

In this section, I would like to move on to the second basic type of focus, which, independent of the givenness or newness of the relevant constituent involved, specifies some relation to a contextually possible or relevant set of alternatives over which it quantifies. ${ }^{81}$ Kiss (1998) calls this type of operator focus "identificational focus".

In yes/no questions of Mandarin Chinese, "identificational focus" in the sense of Kiss is prototypically associated either

- with the use of the "it-cleft" marker shi in combination with the sentence-final question particle $m a$, such as in $(7.1 \mathrm{a})^{82}$, or

- with the use of the compound focus and question operator shi-bu-shi, such as in $(7.1 \mathrm{~b})^{83}$ :

(7.1) a. [shi [Zhang San]] pai ni lai-de ma?

FM Zhang San send you come-AsP QP

'Was it Zhang San that sent you to come?'

b. [shi-bu-shi [Zhang San]] pai ni lai-de?

FM-not-FM Zhang San send you come-Asp

'Was it Zhang San that sent you to come?'

For a better understanding, we have called the identificational focus operator shi the " $i t$ cleft" marker shi up to now. This is only justified from a functional point of view. From a structural point of view, however, this is not quite correct, since no clefting is associated with the use of the marker. ${ }^{84}$ Henceforth, I will call this type of shi the non-assertive "focus marker" (FM) shi, as opposed to the assertion marker shi introduced in section 5. Accordingly, the A-not-A form of this marker shall be rendered as FM-not-FM in interlinear translations.

\subsection{Existential presuppositions, exhaustivity and contrastivity as defining features of identificational focus}

7.1.1. One characteristic of questions like those under (7.1) and their English analogues is that they are based on existential presuppositions. ${ }^{85}$ That is, $(7.1 \mathrm{a}, \mathrm{b})$ are based on the presupposition that 'someone sent the questionee to come'. In contrast, the same ques-

\footnotetext{
80) Drubig (1998), p. 3 .

81 Cf. Drubig (1998) and Molnár (1998).

82 Note that 'inner ATs' can be cleft, as opposed to 'outer ATs' (cf. section 6.4).

83 Following Kiss' notation, I use bold type to indicate identificational focus.

84 Cf. Huang (1981/82), p. 396.

85 Cf. Rooth (1994), p. 390 .
} 
tions without shi or shi-bu-shi, respectively, are not based on such existential presuppositions.

7.1.2. According to Kiss (1998: 245), an identificational focus "exhaustively" identifies "a subset of the set of contextually or situationally given elements for which the predicate phrase can potentially hold". This definition corresponds to Rooth's (1994: 390) claim that "clefts have an assertion or implicature of exhaustive listing".

In terms of semantics, sentences like (7.1a) are derived as follows:

According to Rooth (1996: 275), "focus has the effect of structuring the propositions denoted by sentences: the focus-influenced semantic value of a clause with a single focus is a pair consisting of (i) a property obtained by abstracting the focused position, and (ii) the semantics of the focused phrase". ${ }^{86}$

Applied to (7.1a), for example, this yields the following structured meaning:

(7.2) $<\lambda x[\operatorname{sent}$ to $\operatorname{come}(\mathrm{x}, \mathrm{q})], \mathrm{z}>$

The property in (7.1a) is the property of being an $x$ such that $x$ sent the questionee $q$ to come, while $z$ is the individual denoted by Zhang San.

In a next step, the identificational focus marker shi combines with the structured meaning (7.2), yielding (7.3):

$$
\forall \mathrm{x}[\operatorname{sent} \text { to } \operatorname{come}(\mathrm{x}, q)] \rightarrow \mathrm{x}=\mathrm{z}
$$

(7.3) asserts that nobody other than Zhang San sent the questionee to come. It is exactly this assertion the truth value of which is questioned in (7.1a).

Finally, as a yes/no question, (7.1a) receives the semantic form (7.4), where the question operator $\mathrm{f}$ is instantiated by the yes/no question particle $m a$ :

$$
<\forall \mathrm{f}[\mathrm{f}[\forall \mathrm{x}[\operatorname{sent} \text { to } \operatorname{come}(\mathrm{x}, \mathrm{q})] \rightarrow \mathrm{x}=\mathrm{z}]], \mathrm{ma}>
$$

7.1.3. Kiss (1998: 267) posits that identificational focus is always [+contrastive] in Romanian, Italian and Catalan, while it is [+/-contrastive] in English and Hungarian.

But given that archetypal Chinese identificational focus is functionally equivalent to the $i t$-cleft construction in English, I disclaim that there is any parametric variation in the feature content of identificational focus in either language. My contention is that identificational focus in Chinese and the cleft-clause of the English it-cleft construction are obligatorily [+contrastive].

Basically, this is not a novel idea. I refer to the 'Cleft Focus Principle' of Rochemont (1986: 133, (17)) according to which a cleft focus "must receive a contrastive focus interpretation".

According to Rooth $(1985 ; 1992 ; 1994 ; 1996)$, evoking alternatives is the general function of focus. The set of alternatives, however, is restricted. In any particular case, the specific set of alternatives is "picked up from a specific discourse context or construed pragmatically in a specific situation" $" 87$. Related to identificational focus, this

\footnotetext{
86 See also Krifka (1992), p. 17f.

87 Rooth (1994), p. 389.
} 
statement comes close to Rochemont's claim that the cleft clause of an it-cleft must contain material that is "under discussion"

The following examples are intended to illustrate that Chinese identificational focus phrases regularly contrast with the set of alternatives given in the actual context, regardless of whether the contrast concerned is a more or less implicit or an explicit one:

First of all, consider example (7.5) below representing the case of a negativecontrastive (or replacive) construction of the type ' $\mathrm{X}$, not $\mathrm{Y}^{, 89}$, where the identificational focus phrase, the constituent X ('Zhang San's opinion), is identified by exclusion of its (only) alternative, the constituent Y ('Xiao Wang's opinion'):

Q: Zai zuotian-de hui-shang, ni [v'shi-bu-shi [ $\mathrm{v}^{\prime}$ tongyi-le Zhang San de at yesterday-PART meeting-above you FM-not-FM agree-ASP Zhang San PART yijian]], er bing-mei tongyi Li Si de yijian? opinion but in no way agree Li Si Part opinion 'Was it Zhang San's opinion that you agreed with at yesterday's party?'

A 1: Shide, wo zhi shi tongyi-le Zhang San de yijian. yes I only FM agree-AsP Zhang San Part opinion 'Yes, it was only Zhang San's opinion that I agreed with.'

A2: Bu-shi. Wo [ $\mathrm{v}^{\prime}$ shi [ $\mathrm{v}^{\prime}$ tongyi-le Li Si de yijian]]. no I FM agree-ASP Li Si PART opinion 'No. It was Li Si's opinion that I agreed with.'

A3: \#Dui, erqie wo hai tongyi-le Xiao Wang de yijian. correct and I also agreed-ASP Xiao Wang PART opinion 'Correct, and I agreed with Xiao Wang's opinion as well.'

In this example, the identification of the subset for which the predicate holds results "in the delineation of a complementary subset with clearly identifiable elements", definitely meeting Kiss' requirement for an identificational focus that is [+contrastive] ${ }^{90}$.

Now, compare this example to the question/answer pair (5.16) reproduced below as an example for the assertive question operator shi-bu-shi located in $\mathrm{F}^{\circ}$ :

(5.16) Q: Zai zuotian-de hui-shang, ni shi-bu-shi tongyi-le ta-de yijian? at yesterday-PART meeting-above you AM-not-AM agree-ASP his opinion 'Did you agree with his opinion at yesterday's meeting?'

A: Dui, erqie ni-de yijian wo qishi ye tongyi-le. Correct, and your opinion I basically also agree-Asp 'Correct, and as for your opinion, I basically also agreed.'

Despite the fact that the two structures look very similar, they nevertheless realize different types of focus. Whereas the object of the verb in (5.16Q) lacks the feature of exhaustivity, as (5.16A) shows, this feature is present in (7.5Q), as (7.5A1,A2) show.

\footnotetext{
88 Cl. Rochemont (1986), p. 131.

89 Cf. Drubig (1994), p. $28 f$.

90 Cf. Kiss (1998), p. 268.
} 
Additionally, an identificational focus like in (7.5) allows corrections with shi, as in (7.5A2), as opposed to the information focus in (5.16) which does not.

Finally, (7.5Q) is associated with the existential presupposition that the questionee agreed with somebody's opinion, while (5.16Q) is not associated with this presupposition.

Apart from this, information focus and identificational focus have distinct phonological manifestations. In contrast to identificational focus, information focus is consistent with more than one pitch accent, as we have seen in section 6 in connection with contrastive topics. The position of the identificational focus is the position of the greatest phonological prominence within the clause involved. Thus, the focused phrase in $(7.5 \mathrm{Q})$ is more heavily accented than the information focus in (5.16Q), for which holds: in distributing prominence between head and argument, the latter takes precedence over the former ${ }^{91}$.

In short, the focus in (5.16Q) does not have the feature [+contrastive], whereas the focus in (7.5Q) does have it.

Next, consider example (7.6) below. Let's assume that two people are checking the temperatures of some rooms, while looking around in them:

Q: [shi-bu-shi [ni-de wuzi]] youdian leng?

FM-not-FM your room a bit cold

'Is it your room that is a bit cold?'

A: Dui. Qiqu wuzi hao-duo le.

right other room hao-much PART

'Yes. The other rooms are much better.'

In (7.6Q), the identificational focus 'your room' operates "on a closed set of entities",92 (rooms) whose members are known to the participants of the discourse, meeting Kiss' requirement for contrastive identificational foci as well. Moreover, the contrast is underlined by the answer of the interlocutor, (7.6A).

In $(7.1 \mathrm{a}, \mathrm{b})$, repeated below, 'Zhang San' is identified as the exhaustive subset of a set consisting of a limited circle of people that have the right to send the questionee to the questioner. The identificational focus implicitly contrasts with this set of people:

(7.1) a. [shi [Zhang San]] pai ni lai-de ma?

FM Zhang San send you come-Asp QP

'Was it Zhang San that sent you to come?'

b. [shi-bu-shi [Zhang San]] pai ni lai-de?

FM-not-FM Zhang San send you come-ASP

'Was it Zhang San that sent you to come?'

All in all, I consider it important to stress that the borderline between "clearly identifiable elements" forming a complementary subset with which an identificational focus contrasts and "not clearly identifiable elements" is not clear-cut. This relativizes the dis-

\footnotetext{
91 Cf. Drubig \& Schaffar (2001), p. 3.

92 Ibid., p. 267.
} 
tinction between 'contrastive' and 'non-contrastive' identificational foci made by Kiss (1998). My claim is that contrastivity is an inherent feature of Chinese identificational focus and English it-cleft. To put it simply, identificational focus is always "contrastive'.

\subsection{Syntactic anchoring of identificational focus in the sentence structure}

In my framework, identificational focus is operator focus whose focus feature is composed of a 'contrastivity' feature and an 'exhaustivity' feature. Whereas the former has to check a correlating <contr $>$ feature in the head position of a functional Contrastivity Phrase (ContrP), the latter has to check a correlating <exh $>$ feature in the head position of a functional Focus Phrase (FocP). ${ }^{93}$ Conversely, [+contr] and [+exh] composing the complex focus feature of identificational focus must be discharged in a corresponding Spec-head agreement configuration. This kind of feature checking must take place at LF at the latest.

In the following, let's look at the anchoring of subjects, direct objects and various VP modifiers acting as identificational foci in the sentence structure of Mandarin Chinese.

7.2.1. In Chinese, only the subject of the sentence invariantly realizes the "focus ex situ" language type prototypically instantiated by languages like Hungarian and Arabic $^{94}$. I claim that a sentence like (7.1a) is derived by syntactic movement of the focused phrase which is raised from its base position in $\mathrm{V}^{\prime}$ to its final landing site spec-FocP via spec-ContrP:

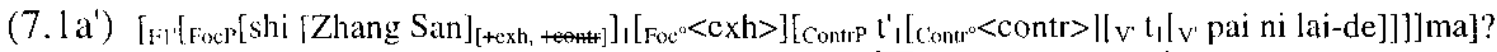

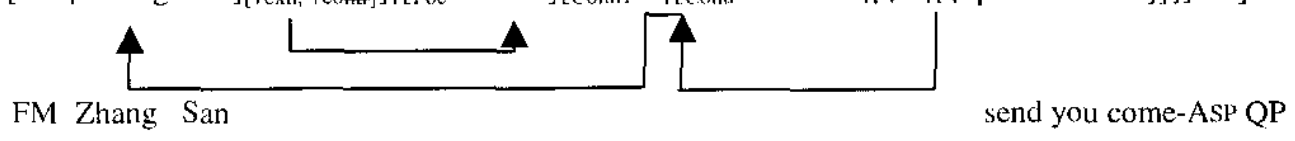

In this structure, the identificational focus operator $s h i$ has assigned its complex focus feature to the subject DP to which shi is Chomsky-adjoined, rendering the focused DP into an operator phrase. Before the operator phrase arrives in spec-FocP where its exhaustivity feature checks the correlating $<\mathrm{exh}>$ feature in $\mathrm{Foc}^{\circ}$, it has made a "stopover" in spec-ContrP in order to check <contr $>$ in Contr ${ }^{\circ}$ by its [+contr] feature. Thus, structures like (7.1 a') do not include an IP.

7.2.2. Direct objects acting as identificational foci realize neither the "focus ex situ" nor the "focus in situ" type. At the level of S-structure, they may occur in two different positions:

First, they may appear in their postverbal base-position. Examples like (7.5Q) and (7.5A2) above instantiate this case in which neither the shi operator in (7.5A2) nor the $s h i$-bu-shi operator in (7.5Q) is adjacent to the identificational focus they are associated with. As a result of this, both operators cannot assign their (complex) focus feature to the object DP at issue. Nevertheless, both the [+contr] feature and the [+exh] feature must be discharged at LF. Consider (7.5A2) as an example for the LF operations triggered by the identificational focus marker shi:

\footnotetext{
93 As for the relative position of both phrases with respect to each other, cf. ou $r$ sentence model (1.1).

94 Cl. Kiss (1998) and Drubig \& Schaffar (2001).
} 


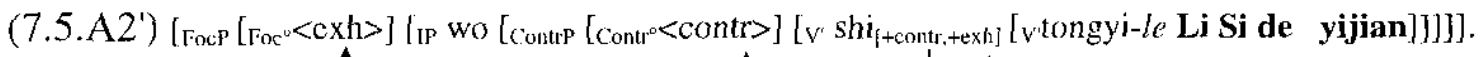

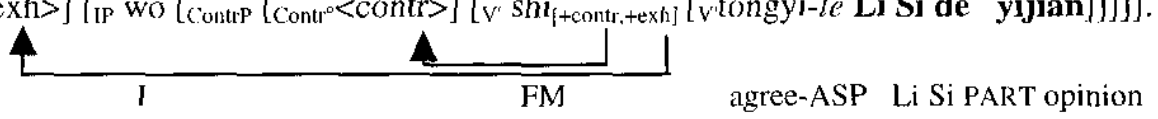

While [+contr] checks <contr $>$ in Contr $^{\circ},\left[+\right.$ exh] checks $<$ exh $>$ in Foc $^{\circ}$, in both cases by 'sister-adjunction' to the relevant features.

Second, they may occur in spec-ContrP, thereby checking <contr> with [+contr]. See example (7.7):

(7.7) Ni shi-bu-shi zhe ben shu bu yao?

you FM-not-FM this $\mathrm{CL}$ book not want

'Is it this book that you do not want to have?'

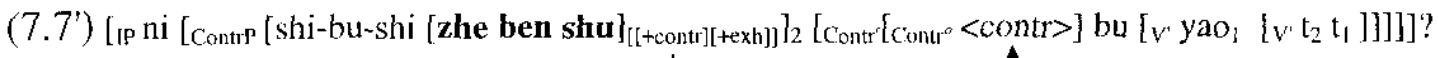

you FM-not-FM this $C L$ book not want

At LF, the exhaustivity feature of the operator phrase must undergo raising to $\mathrm{Foc}^{\circ}$ where it becomes 'sister-adjoined' to the correlating <exh $>$ feature.

Actually, spec-ContrP is a contrastive sentence position available not only to identificational focus phrases (subjects as well as objects) but also to 'object preposing' without any markers as depicted by Qu (1994), Shyu (1995), Ernst \& Wang (1995), N. Zhang (2000), and others. For our purposes, it suffices to say that preposed objects share the feature of contrastivity but not that of exhaustivity with identificational focus.

7.2.3. VP modifiers marked by identificational shi or shi-bu-shi normally remain in situ. In the following example, shi-bu-shi can appear in every position marked by the symbol $\checkmark$, taking narrow scope over the modifier directly following $\mathrm{it}^{95}$ :

(7.8) Xiao Wang ${ }^{\vee}$ zuotian $^{\vee}{ }^{\vee}$ zai zhen-shang ${ }^{\vee}$ yong jiangjin ${ }^{\vee}$ gei nü-pengyou mai-de Xiao Wang yesterday in town-above with premium for girl friend buy-AsP jiezhi?

ring

Since only one shi-bu-shi operator can appear in one and the same sentence, (7.8) has four different identificational focus readings, depending on the actual position of shi$b u$-shi $i^{96}$. Moreover, (7.8) reflects the basic order of VP modifiers with respect to each other:

(7.9) temporal $>$ locative $>$ instrumental $>$ benefactive with $>$ for 'preceding + dominating'

It follows from our approach that, at LF, both the contrastivity feature and the exhaustivity feature carried by an VP modifier are attracted by a correlating feature in Contr $^{\circ}$ and $\mathrm{Foc}^{\circ}$, respectively.

'As for (7.8), cf. Zhang and Fang (1996), p. 79.
'Was it yesterday that Xiao Wang...?', 'Was it in the town that Xiao Wang...?' elc. 
In fact, the claim that focused adjuncts must undergo LF movement has already been made by Huang (1982: 532f.). Huang refers to the ungrammaticality of structures like (7.10), which exhibit typical Island effects: ${ }^{97}$

(7.10) *[np[s Zhangsan shi zuotian mai] de shu] hen hao. Zhangsan FO yesterday buy DE book very good

Huang 1982: 533, (32))

*'The book that it was yesterday that Zhangsan bought is very good.'

Alternatively, at least locative and temporal VP modifiers marked by identificational shi or shi-bu-shi can be raised to spec-FocP via ContrP. This applies to our examples (6.9) and $(6.15)$ given in section 6.

7.2.4. Assertive $s h i$-bu-shi as treated in section 5 and identificational shi-bu-shi share the property of possessing a question feature. Yet whereas the question feature of assertive shi-bu-shi is discharged within F2P before 'Spell-Out', the question feature of identificational shi-bu-shi must be discharged by attraction at the level of LF. That is to say, the question feature [+Q] conveyed by identificational shi-bu-shi is attracted by an abstract feature, $\langle\mathrm{Q}\rangle$, located in $\mathrm{F} 1^{\circ}$.

A problem connected with this LF operation is that $[+Q]$ cannot be 'sister-adjoined' to $\langle\mathrm{Q}\rangle$, because the Force 1 Phrase of Chinese is head-final. This typological peculiarity of Chinese most clearly manifests itself in the sentence-final position of the yes/no question particle $m a$. Compare $(7.1 \mathrm{a}) /\left(7.1 \mathrm{a}^{\prime}\right)$ above with the tree structure $(7.1 \mathrm{a})$ :

(7.1) a".

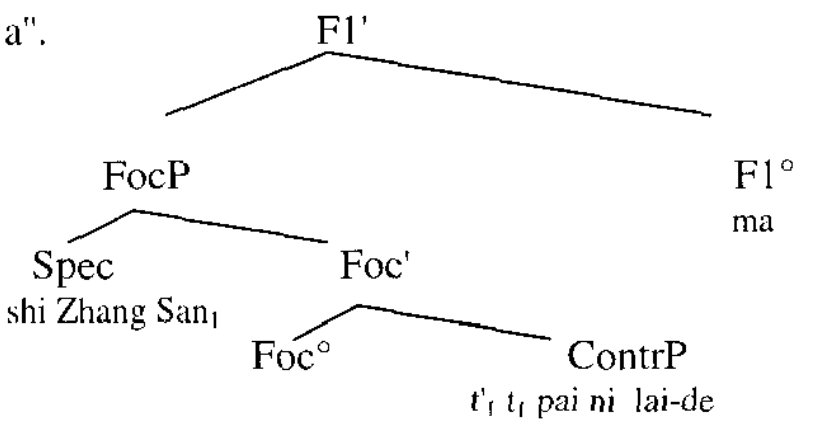

Now, let's consider the LF of $(7.1 \mathrm{~b})$ where $F 1^{\circ}$ is not directly accessible to the [+Q] feature of the operator phrase marked by shi-bu-shi.

Chomsky's checking theory requires that feature checking takes place within the 'checking domain' of the head whose features are being checked. A checking domain of a head $X^{\circ}$ includes anything adjoined to the head, to X' or XP. ${ }^{98}$

Therefore checking theory permits that the question feature of the operator phrase under discussion is Chomsky-adjoined to F1'. I opt for this solution, following Whitman (1997: 4) who claims that right-headed X'-structures necessarily lack a Spec position, because Spec-head agreement requires adjacency between the head element and its Specifier. ${ }^{99}$ Assuming this to be true, the LF of (7.1b) must be (7.1 b'):

97 See also Chiu (1993: 130ff.) who cites this and other examples.

98 See also Han (1998: 5f.).

99 By contrast, Kayne (1994) presupposes a left-headed clause structure across languages. Based on this assumption, he claims that "final complementizers reflect the leftward movement of IP into Spec, CP" (p. 53). Kayne's proposal is problematic insofar as it conflicts with natural 'economy principles' in the derivation and representation of sentences, suggested by Chomsky (1995: 198): "The system tries to 
(7.1) b. [shi-bu-shi [Zhang San]] pai ni lai-de?

FM-not-FM Zhang San send you come-AsP

'Was it Zhang San who sent you to come?'

(7.1) $b^{\prime}$

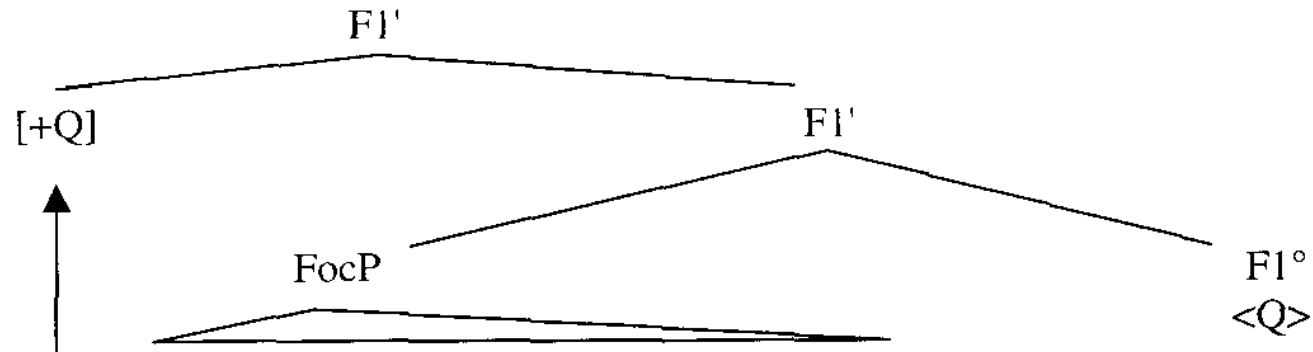

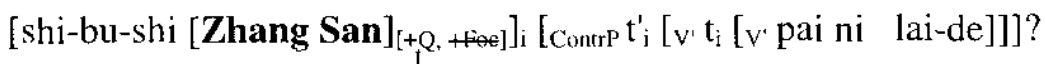

FM-not-FM Zhang San

send you come-ASP

As soon as [+Q] is adjoined to $\mathrm{Fl}^{\prime}$, it is able to check the correlating $\langle\mathrm{Q}>$ feature $\mathrm{c}$-commanded by it.

7.2.5. Referring to Li (1992), Schaffar \& Chen (2001: 861) observe that the indefinite reading of wh-expressions in subject position is licensed by the shi-bu-shi operator not only in (7.11) but also in (7.12):

(7.11) Shi-bu-shi shenme ren xihuan ta?

FM-not-FM what man like he

'Does someone like him?'

(7.12) Shei / shenme ren shi-bu-shi xihuan ta?

who / what man FM-not-FM like he

'Does someone like him?'

Schaffar \& Chen conclude that Li's explanation that the binding of a wh-word is achieved via c-command cannot be correct, since the wh-word in subject position can in fact be bound independently of the position of shi-bu-shi. Schaffar \& Chen admit that they "cannot explain in detail how this binding is achieved".

In our system, this binding is achieved by the requirement that the question feature of the shi-bu-shi operator must undergo LF-raising. Once Chomsky-adjoined to F1' along the principles outlined above, the question feature [+Q] c-commands the wh-expression in subject position. Thus, (7.12) does not falsify Li's and our claims.

\section{Pragmatic use of yes/no question sentences}

\subsection{Neutral and non-neutral contexts}

Linguists such as Chao (1968), Li \& Thompson (1981), Yuan (1993), Xu \& Shao (1998), Chu (1998) and B. Zhang (1999) hold the view that A-not-A questions are pro-

reach PF 'as fast as possible', minimizing overt syntax." But see D. Xu (1997) and N. Zhang (1997), who uncritically apply Kayne's proposal to Chinese. 
totypical yes/no questions, pure information questions used in neutral contexts in which the questioner does not make any assumptions about the possible answer in advance, whereas ma questions are predominantly used in non-neutral contexts, and include weak negative (or, in special cases, positive) pre-assumptions about the possible answer.

B. Zhang (1999: 298f.) observes that ma questions often come close to rhetorical questions, expressing an attitude of total disbelief, or a sceptical attitude, if they contain additional affirmative or negative particles. Even a $m a$ question asked in an absolutely neutral form can express doubts - for example, if someone in a student's mess hall asks an about fifty-year old man:

(8.1) Ni shi xuesheng ma? you be student QP 'Are you a student?'

On the other hand, Zhang does not deny that ma questions can be put in neutral contexts, such as (8.2) asked as a purely informational question:

Q: Bisai jieshu-le ma? match finish-AsP QP 'Has the match finished?'

A: Jieshu-le. / Hai mei you jieshu. / ?Shi-de. ${ }^{100}$ finish-Asp Yet not Asp finish. yes

Discussing A-not-A questions from a pragmatic point of view, Shao (1996: 120ff.) convincingly proves that they, just like ma questions, can be combined with positive or negative pre-assumptions:

(8.3) Nin shuo zhe ren ke'e-bu-ke'e? Wo ting nin-de hua, you say this man repugnant-not-repugnant I hear your words gang yi gen ta shangliang, ta jiu hengzhe lai le! only just with he discuss he already become abusive PART

'Now you tell me, isn't this person repugnant? I heard what you said; you had hardly started discussing things with him before he became abusive.'

(8.4) Zhe ge xiaoxi yaoshi chuanchuqu, wo the ge guan hai dang-bu-dang? this CLnews if get out I this $\mathrm{CL}$ official still perform-not-perform 'If this news gets out, will I be able to keep my job?'

\subsection{Concluding remarks}

To summarize, both ma questions and A-not-A questions can serve as neutral information questions, and both types of question can be used in non-neutral contexts associated with negative or positive pre-assumptions about the answer. In this respect there is little difference between them.

However, ma questions have the decisive advantage of their question operator having scope over the whole sentence. This makes them adaptable to different types of focus, i.e., it makes them consistent with both information focus and identificational focus, as

100 Note that neutral information questions are commonly answered by repeating the verb in its affirmative or negative form. 
we have seen in this paper. And it also makes them compatible with (core) adjuncts operating over propositions.

By contrast, the question operator of A-not-A and A-not questions has a scope that is restricted to the predicate. Yes/no questions of this type are incompatible with identificational focus and Ernst's core adjuncts, because their question operator does not undergo LF-raising to Fl' (or "Comp"), as we have shown. Instead, they are typed clause-internally in $\mathrm{F}^{\circ}$.

Perhaps, it is this semantic-pragmatic advantage of ma questions that leads the younger inhabitants of Shanghai to increasingly prefer the sentence-final question particle $v a$ to the sentence-internal question operator $a$ mentioned in section $5 .{ }^{101}$

If $\mathrm{I}$ am on the right tack concerning the reasons for the decline of the use of the sentence-internal question particle $a$ and the increase of the use of the sentence-final particle $v a$ in Shanghainese, then we have a very natural explanation for an intriguing fact discovered by Lui Shuxiang (1954, vol 2, p. 249) ${ }^{102}$ : the fact that the negative particle $w u$ of Classical Chinese which appeared in the sentence final position of yes/no questions has evolved into the yes/no question particle ma of Modern Mandarin Chinese. Conversely, this means that the modern question particle ma can be traced back to one of the $\mathrm{V}(\mathrm{O})$-not patterns of Classical Chinese.

For us, the decisive phenomenon is that the evolution of both the negative particle ve in Shanghainese and the negative particle $w u$ in Classical Chinese into pure yes/no question particles was accompanied by the extension of the scope of these particles over the whole sentence. I come to the conclusion that this evolution was evoked by the pragmatic requirements of language use.

\section{References}

Altmann, Hans (1981): Formen der 'Herausstellung' im Deutschen. Rechtsversetzung, Linksversetzung, Freies Thema und verwandte Konstruktionen. Tübingen: Max Niemeyer.

AOUN, JOSEPH \& LI, YEN-HUI AUDREY (1989): Scope and Constituency. In: Linguistic Inquiry 20: $141-172$.

Aoun, JosePh \& LI, Yen-Hui Audrey (1993): Syntax of Scope. Cambridge, MA \& London: MIT Press.

AQvisT, LENNART (1965): A New Approach to the Logical Theory of Interrogation, Part I, Analysis. Upsala: Almqvist \& Wiksell,

ASHER, NICHOLAS (1993): Reference to Abstract Objects in Discourse. Dordrecht, Boston \& London: Kluwer Academic Publishers,

BAKER, C. L. (1970): Notes on the description of English questions: The role of an abstract question morpheme. In: Foundations of Language 6: 197-219.

BIQ, YUNG-O (1988): From focus in proposition to focus in speech situation: cai and jiu in Mandarin Chinese. In: Journal of Chinese Linguistics 16 (1): 72-107.

BISANG, WALTER (1991): Verb Serialization, grammaticalization and attractor positions in Chinese, Hmong, Vietnamese Thai and Khmer. In: H. Seiler \& W. Premper (eds.), Partizipation: Das sprachliche Erfassen von Sachverhalten, 511-562. Tübingen: Gunter Narr.

${ }^{101} \mathrm{Cl}$. Yuan (1993: 108) and $\mathrm{Xu} \&$ Shao (1998: 88). Interestingly enough, according to Shao (1996: 113), the sentence-final particle va of Shanghainese has evolved out of the negation particle ve used in sentence-final position plus the modal particle $l a$, i.e., ve+la $\rightarrow v a$.

102 See also Wang Li (1958), vol. 2, p. 452. 
BISANG, Walter (1992): Das Verb im Chinesischen, Hmong, Vietnamesischen, Thai und Khmer. Vergleichende Grammatik im Rahmen der Verbserialisierung, der Grammatikalisierung und der Attraktorpositionen. Tübingen: Gunter Narr.

BOLlaND, JUlITA (1993): Conditionals in Mandarin. In: Lingua Posnaniensis XXXV: 95-113.

Chafe, Wallace L. (1976): Givenness, Contrastiveness, Definiteness, Subjects, Topics and Point of View. In: CH. N. LI (ed.), Subject and Topic, 25-55. New York: Academic Press.

ChaO, YUEn REN (1968): A Grammar of Spoken Chinese. Berkeley \& Los Angeles: University of California Press.

CHEN, LANSUN \& SCHAFFAR, WOLFRAM (1997): Ja/Nein-Fragen im Mandarin, im Xiang und im Thailändischen. Arbeitspapiere des SFB 340, Bericht Nr. 94.

CHENG, Lisa LaI SHEN (1991): On the Typology of WH-Question. Ph. D. Dissertation, MIT.

Cheng, Lisa LaI-Shen, Huang, C.-T. James, \& TANG, C. C. JAne (1996): Negative Particle Questions: A Dialectical Comparison. In: James R. Black \& Virginia Motapanyane (eds.), Microparametric syntax and Dialect Variation, 41-79. Amsterdam \& Philadelphia: John Benjamins.

Chierchia, Gennaro \& MCConnell-Ginet, Sally (1990): Meaning and Grammar: An Introduction to Semantics. Cambridge, MA \& London: MIT Press.

CHIU, BonNiE Hui-CHun (1993): The Inflectional Structure of Mandarin Chinese, Diss., Los Angeles.

CHO, EuN (1997): The Dual Nature of Contrastive Topic and LF Movement. In: K. Singer, R. Eggert \& G. Anderson (eds.), CLS 33, Papers from the main session, 43-55. Chicago, IL.

CHOMSKY, NOAM \& LASNIK, HOWARD (1977): Filters and Control. In: Linguistic Inquiry 8: 425-504.

CHOMSKY, NOAM (1973): Conditions on Transformations, in S. R. Anderson \& P. Kiparsky (eds.), A Festschrift for Morris Halle, 232-286. New York: Holt, Rinehart \& Winston.

CHOMSKY, NOAM (1982): Lectures on Government and Binding: The Pisa Lectures. Dordrecht \& Cinnaminson: Foris Publications.

CHOMSKY, NOAM (1995): The Minimalist Program. Cambridge, MA \& London: MIT Press.

CHOMSKY, NOAM (1998): Minimalist Inquiries: The Framework, in MIT Working Papers in Linguistics 15.

Chomsky, NOAm (1999): Derivation by Phase [MIT Occasional Papers in Linguistics, 18]. Cambridge, MA.

CHU, CHAUNCEY C. (1983): A Reference Grammar of Mandarin Chinese for English Speakers. New York, Frankfort on the Main, Berne: Peter Lang.

Chu, Chauncey C. (1998): A discourse Grammar of Mandarin Chinese. New York: Peter Lang.

DAI, JoHN XIANG-LING (1993): The Negator BU and a Morphosyntactic Analysis of A-not-A Qestions in Chinese. In: L. M. Dobrin, L. Nichols, \& R. M: Rodrigues, (eds.), Papers from the 27th Regional Meeting of the Chicago Linguistic Society 1991, Part Two, The Parasession On Negation, CLS 27, 17-29. Chicago.

Di Sciullo, AnNa Maria \& Williams, EdWin (1987): On the Definition of Word. Cambridge, MA \& London: MIT Press.

DIK, SIMON C. (1997): The Theory of Functional Grammar. Part 1: The Structure of Clause. Second, revised version. Berlin \& New York: Mouton de Gruyter.

Downing, BRUCE T. (1978): Some Universals of Relative Clause Structure. In: Joseph H. Greenberg ed., Universals of Human Language, 375-418. Standford University Press.

DRAGUNOV, A. A. (1960[1952]: Untersuchungen zur Grammatik der modernen chinesischen Sprache. Berlin: Akademie-Verl.

DRUBIG, HANS BERHARD (1994): Island Constraint and the Syntactic Nature of Focus and Association with Focus. Arbeitspapiere des Sonderforschungsbereichs 340, Bericht Nr. 51.

DRUBIG, HANS BERNHARD \& SCHAFFAR WOLFRAM (2001): Typologie der Informationsstruktur: Einige weiterführende Perspektiven, Abschlußkolloquium des DFG-Schwerpunkts Sprachtypologie, Berlin 1.-2. 12.01, 1. Teil. 
DRUBIG, Hans Bernhard (1998): Focus and Connectedness: Towards a Typology of Focus Construction. DFG-Schwerpunkt: Sprachtypologie. Universität Tübingen.

DRYER, MATTHEW (1992): The Greenbergian Word Order Correlations. In: Language 68: 81138.

ERNST, THOMAS \& WANG, CHENGCHI (1995): Object preposing in Mandarin Chinese. In: Journal of East Asian Linguistics 4: 235-260.

ERNST, THOMAS (1988): Chinese Postpositions? - Again. In: Journal of Chinese Lingustics 16 (2): 219-245,

ERNST, THOMAS (1994): Conditions on Chinese A-not-A Questions. In: Journal of East Asean Linguistics 3: 241-264.

ERNST, THOMAS (1995): Negation in Mandarin Chinese. In: Natural Language and Linguistic Theory 13: 665-707.

FALK, YEHUDA N. (1991): Case: abstract and morphological. In: Linguistics 29: 197-230.

FUKUI, NAOKI \& SAITO MAMORU (1992): Spec-head agreement, X'-compatibility, and optimality. Paper presented at MIT Colloquium, Cambridge MA.

FUKUI, NAOKI \& SPEAS, MARGARET (1986): Specifiers and Projection. In: MIT Working Papers in Linguistics 8: 128-172.

FUKUI, NAOKI (1991): Strong an weak barriers: remarks on the proper characterization of barriers. In: H. Nakajima (ed.), Current English Linguistics in Japan, 78-93. Berlin: de Gruyter.

FUKUI, NAOKI (2001): Phrase Structure. In: M. Baltin \& C. Collins, The Handbook of Contemporary Syntactic Theory, 374-406. Blackwell Publishers.

GABELENTZ, GEORG VON DER (1901[1891]): Die Sprachwissenschaft, ihre Aufgaben, Methoden und bisherigen Ergebnisse. Leipzig. 2., vermehrte und verb. Aufl.

Gasde, Horst-DieTer \& PAUL, Waltraud (1996): Functional categories, topic prominence, and complex sentences in Mandarin Chinese. In: Lingustics 34: 263-294.

GASDE, HoRST-Dieter (1993): Lexikalische und funktionale Kategorien des chinesischen Satzes. In: Sprachtypol. Univ. Forsch. (STUF), Berlin 46 (4): 239-274.

GASDE, HORST-DIETER (1998): Topics, Foci and Sentence Structure in Mandarin Chinese. In: Sprachtypol. Univ. Forsch. (STUF), Berlin 51 (1): 43-94.

GOODALL, GRANT (1999): Accusative case in passive. In: Linguistics 37 (1): 1-12.

GREENBERG, JOSEPH H. (1966): Some Universals of Grammar with Particular Reference to the Order of Meaningful Elements. In: J. H. Greenberg (ed.), Universals of Language, 37-113. Cambridge, MA \& London: MIT Press.

GROENENDIJK, JEROEN \& STOKHOF, MARTIN (1997): Questions. In: J. van Benthem \& A. ter Meulen (1997), Handbook of Logic and Language, Chapter 19. Cambridge, MA: MIT Press.

Grohmann, Kleanthes (2000): Prolific Peripheries: A Radical View from th Left. Ph. Diss., University of Maryland.

Gundel, JEANETTE K. (1988[1974]): The Role of Topic and Comment in Linguistic Theory. New York \& London: Garland Publishing, Inc.

HAIMAN, JOHN (1978): Conditionals are topics. In: Language 54 (3): 564-589.

HAN, CHUNG-HYE (1998): The Structure and Interpretation of Imperatives: Mood and Force in Universal Grammar. Ph. D. Dissertation, University of Pennsylvania.

HAWKINS, JOHN A. (1983): Word Oreder Universals. New York \& London: Academic Press.

HE, YUAN JIAN (1998): 'A-not-A' Quesitions Revisited. In: Y. Gu (ed.), Studies in Chinese Linguistics, 1-21. Linguistic Society of Hong Kong.

HÖHLE, TILMAN N. (1992): Über Verum-Fokus im Deutschen. In: Joachim Jacobs (ed.), Informationsstruktur und Grammatik, 112-141. Opladen: Westdeutscher Verl.

HORnStEIn, NORBERT (1995): Logical Form - From GB to Minimalism. Oxford, UK \& Cambridge, MA: Blackwell.

HUANG, C.-T. JAMES (1981/82): Move WH in a Language without WH Movement. In: The Linguistic Review 1: 369-416. 
HuANG, C.-T. JAmES (1982): Logical Relations in Chinese and the Theory of Grammar, Ph. D. Dissertation, MIT, Cambridge/Mass.

HuANG, C.-T. JAMES (1984): On the Distribution and Reference of Empty Pronouns. In: Linguistic Inquiry 15: 531-574.

HuANG, C.-T. JAMES (1987): Existential Sentences in Chinese and (In)definiteness, in R. J. REUland \& A. G. B. TER MEULEN, The Representation of (In)definiteness, 226-253. Cambridge, MA: MIT Press.

Huang, C.-T. James (1988): Wo pao de kuai and Chinese Phrase Structure. In: Language 64: 274-311.

HuANG, C.-T. JAMES (1989): Pro-drop in Chinese: a generalized control theory. In: O. Jaeggli \& K. J. Safir (eds.), The null parameter, 215-238. Dordrecht, Boston \& London: Kluwer Academic Publishers.

HUANG, C.-T. JAMES (1991): Modularity and Chinese A-not-A Questions. In: C. Georgopoulos \& R. Ishihara (eds.), Interdisciplinary Approaches to Language, Essays in Honor of S.-Y. Kuroda, 305-332. Dordrecht, Boston \& London: Kluwer Academic Publishers.

HUANG, YAN (1994): The syntax and pragmatics of Anaphora, A study with special reference of anaphora. Cambridge University Press.

HUANG, YAN (1995): On null subjects and null objects in generative grammar. In: Linguistics $33(6): 1081-1123$.

HUANG, YAN (2000): Anaphora: A Cross-linguistic Approach. Oxford University Press.

JACOBS, JOACHIM (1984): Funktionale Satzperspektive und Illokutionssemantik. In: Linguistische Berichte 91: 25-58. Opladen: Westdeutscher Verl.

JACOBS, JOACHIM (2001): The dimension of topic-comment. In: Linguistics 39 (4): 641-681.

KAYNE, RICHARD S. (1994): The antisymmetry of Syntax. Cambridge/Mass. \& London: MIT Press.

KIPARSKY, PAUL (1991): Positional Licencing, Berlin: Institute for Advanced Study, Unpubl. Ms.

KISS, KATALIN É. (1994): Discourse-configurality in the languages of Europe. Unpubl. Ms., EUROTYP Project.

KisS, KATALIN É. (1998): Identificational Focus vs. Information Focus. In: Language 74 (2): 245-273.

KLein, Wolfgang \& Ll, Ping \& Hendriks, Henriette (2000): Aspect and assertion in Mandarin Chinese. In: Natural Language \& Linguistic Theory 18: 723-770.

KOOPMAN, HILDA \& SPORTICHE, DOMINIQUE (1991): The position of subjects. In: Lingua 85: 211-258.

KoOPMAN, HILDA (1984): The Syntax of Verbs - From Verb Movement Rules in the Kru Languages to Universal Grammar. Dordrecht \& Cinnaminson: Foris Publications.

KRATZER, ANGELIKA (1988): Stage-level and individual-level predicates. In: Manfred Krifka, (ed.), Genericity in Natural Language, Proceedings of the 1988 Tübingen Conference, 247284, Seminar für natürlich-sprachliche Systeme der Universität Tübingen.

Kratzer, Angelika (1995): Stage-Level and Individual-Level Predicates. In: Gregory N. Carlson \& Francis J. Pelletier (eds.), The Generic Book, 125-175. Chicago \& London: The University of Chicago Press.

KRIFKA, MANFRED (1992): A Compositional Semantics for Multiple Focus Constructions. In: J. JACOBS (ed.), Informationsstruktur und Grammatik. Linguistische Berichte. Sonderheft 4/ 1991-92, 17-53.

KRIFKA, MANFRED (2000): Topics and Speech Acts. Paper at the 11. Wuppertaler Linguistisches Kolloquium, 17.-18.11.00.

KRIFKA, MANFRED (2001a): For a structured meaning account of questions and answers (revised version), in C. Fery \& W. Sternefeld (eds.), Audiatur Vox Sapientia. A Festschrift for Arnim von Stechow [Studia Grammatica 52], 287-319. Berlin: Akademie-Verl.

KRIFKA, MANFRED (2001b): Quantifiying into question acts (revised version), to appear in $\mathrm{Na}$ tural Language Semantics. 
KROCH, ANTHONY S. (2001): Syntactic Change. In: M. Baltin \& C. Collins, The Handbook of Contemporary Syntactic Theory, 699-729. Blackwell Publishers.

KURODA, SIGE YUKI (1972-73): The categorial and the thetic judgment. In: Foundations of Language 9: 153-185.

LABEAUX, DAvid (1988): Language Acquisition and the Form of the Grammar. PhD dissertation, University of Massachusetts, Amberst.

LaKA, M. I. (1990): Negation in Syntax: On the Nature of Functional Categories and Projections. Ph. D. Diss., MIT.

LAMBRECHT, KNUD (1994): Information structure and sentence form: Topic, focus, and the mental representations of discourse referents. Cambridge University Press.

LASNIK, HOWARD \& STOWELL, TIM (1991): Weakest Crossover. In: Linguistic Inquiry 22: 678720.

LeE, Po-lun PepPina \& Pan Haihua (2001): The Chinese negation marker $b u$ and its association with focus. In: Linguistics 39 (4): 703-731.

LEHMANN, CHRISTIAN (1982): Thoughts on Grammaticalization - A programmatic sketch, Vol. I, Arbeiten des Kölner Universalien-Projekts (akup), 1-190.

Ll, ChARles N. \& THOMPSON, SANDARA A. (1974): Chinese as a topic-prominent language. Paper presented at the 7 th International Conference on Sino-Tibetean Language and Linguistics, Atlanta, Ga.

Ll, Charles N. \& Thompson, Sandara A. (1976): Subject and Topic: A New Typology of Language. In: C. N. LI (ed.), Subject and Topic. 457-489. New York: Academic Press.

Li, Charles N. \& ThOMPSON, SANDara A. (1981): Mandarin Chinese, A Functional Reference Grammar. Berkeley, Los Angeles: University of California Press.

LI, Yen-HUl AUdREY (1990): Order and Constituency in Mandarin Chinese. Dordrecht, Boston \& London: Kluwer Academic Publisheres.

LI, YEN-HUI AUdREY (1992): Indefinite Wh in Mandarin Chinese. In: Jounal of East Asian Linguistics 1: 125-155.

L1, YING-CHE (1980): The historical development of the coverb and the coverbal phrase in Chinese. In: Journal of Chinese Linguistics 8 (2): 273-293.

Light, TiмотнY (1979): Word Order and Word Order Change in Mandarin Chinese. In: Journal of Chinese Linguistics 7: 149- 180.

LIPPERT, WOLFGANG (1965): Das Satzthema in der modernen chinesischen Sprache. InauguralDissertation, Johann Wolfgang Goethe-Universität, Frankfurt/Main.

LIU YUEHUA \& PAN WENYU \& GU WEI (1983): Shiyong xiandai hanyu yufa: (A practica! grammar of Modern Chinese). Beijing: Foreign Languages Teaching and Research Publishing House.

LIU, DANQING (2000): Wuyu zhong de qianzhici, houzhici ji qi xiangguan yuxu leixing (Adpositions and the Related Word Order Types in Wu Dialects), Ph. D. Dissertation, City Universisty of Hong Kong.

LÓPEZ, LUIS \& VILLALBA, XAVIER (2000): Toward a minimalist analysis of the left periphery: dislocation in Catalan. Ms.

LÜ, SHUXIANG (1954[1941]): Zhongguo wenfa yaolüe (Outline of Chinese Grammar). Shanghai Printing House.

MAIENBORn, Claudia (1996): Situation und Lokation - Die Bedeutung lokaler Adjunkte von Verbalprojektionen [Studien zur deutschen Grammatik 53]. Tübingen: Stauffenburg Verl.

MALLINSON, GRAHAM \& BLAKE, BARRY J. (1981): Language Typology - Cross-linguistic Studies in Syntax. Amsterdam \& New York \& Oxford: North-Holland Publishing Company.

MCCAWLEY, JAMES D. (1994): Remarks on the Syntax of Mandarin Yes-No-Questions. In: Journal of East Asian Linguistics 3: 179-194.

MEI, KUANG (1980): Is Modern Chinese really a SOV language? In: Cahiers de Linguistique Asie Orientale 7: 23-45.

MOLNÁR, VALÉRIA (1991): Das TOPIC im Deutschen und im Ungarischen. Stockholm: Almqvist \& Wiksell International. 
MOLNÁR, VALÉRIA (1998): Topic in focus: On the syntax, phonology, semantics and pragmatics of the so-called 'contrastive topic' in Hungarian and German. In: Acta Linguistica Hungarica 45 (1-2): 89-166.

Mulder, René \& Sybesma, Rint (1992): Chinese is a VO language. In: Natural Language and Linguistic: Theory 10: 439-476.

OHTA, TAtsuo (1987): Zhongguo yu lishi wenfa (A Historical Grammar of Modern Chinese). Beijing: Beijing University Press.

OHTA, TATSuO (1991): Hanyu shi tong kao (A general review of the history of Chinese language), Chongqing Publishing Company.

PARIS, MARIE-ClaUde (1995): The Interaction between Focus Operators and Types of Predications in Mandarin. In: J. CAMACHO \& L. CHOUEIRI (eds.), The 6th North American Conference on Chinese Linguistics, NACCL 6, Volume 1, 149-158. Los Angeles: GSIL, University of California.

PARIS, MARIE-Claude (1998): Focus operators and types of predication in Mandarin. In: Cahiers de Linguistique Asie Orientale 27(2): 139-159.

Paul, Waltraud (1982): Die Koverben im Chinesischen, Institut für Sprachwissenschaft, U Köln, Arbeitspapier 40.

Peyraube, Alain (1989): Zao qi 'ba' zi ju de ji-ge wenti (Some problems of early ba sentences). In: Yuwen yanjiu 30: 1-9.

PLATZACK, Christer (1999): Multiple Interfaces, to be published in U. Nikanne \& E. van der Zee (eds.), Conceptual Structure and its Interfaces with Other Modules of Representation, Oxford University Press.

Qu, Yanfeng (1994): Object Noun Phrase Dislocation in Mandarin Chinese. Ph. D. Dissertation, The University of British Columbia.

RADFORD, ANDREW (1981): Transformational Syntax: A student's duide to Chomsky's extended standard theory. Cambridge University Press.

RADFORD, ANDREW (1997): Syntactic theory and the structure of English - An minimalist approach. Cambridge University Press.

Reinhart, Tanya (1982): Pragmatics and Linguistics: An Analysis of Sentence Topics, Bloomington: Indiana University Linguistics Club. See also in: Philosophica 27, 1981, 5394.

RIZzI, LuiGI (1997): The fine structure of the left periphery. In: L. Haegeman (ed.), Elements of Grammar: Handbook in Generative Syntax. 281-337. Dordrecht, Boston \& London: Kluwer.

RoCHEMONT, MichaEl S. (1986): Focus in generative grammar. Amsterdam \& Philadelphia: John Benjamins.

Rochemont, Michael S. \& Culicover, Peter W. (1990): English Focus Construction and the Theory of Grammar. Cambridge University Press.

ROOTH, MATs (1985): Association with focus. Ph. D. Dissertation, University of Massachusetts.

ROOTH, MATS (1992): A theory of focus interpretation. In: Natural Language Semantics 1: 75116.

ROOTH, MATS (1994): Association with focus or association with presupposition? In: Peter Bosch \& Rob van der Sandt (eds.), Focus \& Natural Language Processing, Volume 2: Semantics, 389-397. IBM Working Papers of the Institute for Logic and Linguistics.

RooTH, MATS (1996): Focus. In: Shalom Lappin (ed.), The Handbook of Contemporary Semantic Theory, 271-297. Cambridge, MA: Blackwell.

Ross, Claudia (1995): Temporal and Aspectual References in Mandarin Chinese. In: Journal of Chinese Linguistics 23: 87-136.

SADOCK, JERROLD M. \& ZWICKY, ARNOLD M. (1985): Speech act distinctions in syntax. In: T. Shopen (ed.), Language typology and syntactic description, 155-196. Cambridge University Press.

SAITO, MAMORU \& FKUI, NAKOI (1998): Order in Phrase Structure and Movement. In: Linguistic Inquiry 29: 439-474. 
SASSE, HANS-JÜRGEN (1987): The thetic/categorial distinction revisited. In: Linguistics 25: 511 580.

SCHAFFAR, WOLFRAM \& CHEN, LANSUN (2001): Yes-no questions in Mandarin and the theory of focus. In: Linguistics 39 (5): 837-870.

SHAO, JINGMIN (1996): Xiandai hanyu yiwen ju yanjiu (Studies on interrogative sentences of Modern Chinese). Huadong Teachers University Publishing House.

SIEWIERSKA, ANNA (1988): Word Order Rules. London, New York \& Sydney: Croom Helm.

SIEWIERSKA, ANNA (1991): Functional Grammar. London \& New York: Routledge

SpEAS, MARGaret (1990): Phrase Structure in Natural Language. Dordrecht, Boston \& London: Kluwer Academic Publishers.

STEUBE, ANITA (1999): Ein kognitionswissenschaftlich basiertes Modell für Informationsstrukturierung (in Anwendung auf das Deutsche). Manuskript.

SYBESMA, RINT (1999): The Mandarin VP. Dordrecht: Kluwer Academic Publisheres.

TAGLICHT, JOSEF (1984): Message and Emphasis. On Focus and Scope in English. London: Longman.

TAl, JAMES HAO-I (1985 [=1973]): Chinese as a SOV language. In: S-h. Teng (ed.), Readings in Chinese Transformational Syntax, 341-354. Taipei: The Crane Publishing Co., Ltd.

TANG, TING-CHI (1983): Focusing Constructions in Chinese: Cleft Sentences and Pseudo-cleft Sentences. In: T-C. Tang \& Robert L. Cheng \& Ying-che Li (eds.), Studies in Chinese Syntax and Semantics, Universe and Scope: Presupposition and Quantification in Chinese, 127-226. Taipei: Student Book Co., Ltd.

TRAVIS, LiSA (1984): Parameters and Effects of Word Order Variation. Unpublished Ph.D. dissertation, MIT.

TSAO, FENG-FU (1990): Sentence and Clause Structure in Chinese: A Functional Perspective. Taipei: Student Book Co., Ltd.

VANDERVEKEN, DANIEL (1990): Meaning and speech acts, Volume 1, Cambridge University Press.

vON STECHOW, ARNIM (1991): Current Issues in the Theory of Focus. In: A. von Stechow \& D. Wunderlich (eds.), Semantics, An International Handbook of Contemporary Research, 804-825. Berlin \& New York: Walter de Gruyter.

WANG, LI (1958): Hanyu shi gao (Outline of the history of Chinese language), Vol. 2, Beijing: Science House.

WANG, WILLIAM S.-Y. (1965): Two aspect markers in Mandarin. In: Language 41: 457-470.

WHITMAN, JOHN (1997): Kayne 1994: p. 143, fn.3. OLF '97: University of Ottawa. Handout.

WURZEl, WOlFGANG UlLriCH (2000): Was ist ein Wort? In: R. Thieroff et al. (eds.), Deutsche Grammatik in Theorie und Praxis, 29-42. Tübingen: Max Niemeyer.

XU, DING (1997): Functional Categories in Mandarin Chinese [HIL Dissertations 26]. Ph. D. Dissertation, University Leiden.

Xu, Liejiong \& Langendoen, D. Terence (1985): Topic Structures in Chinese. In: Language $61(1): 1-27$.

XU, LiEJIONG \& LIU, DANQING (1998): Huati-de jiegou yu gongneng (Structure and functions of topics), Shanghai Educational Publishing House.

XU, LIEJIONG \& SHAO JINGMIN (1998): Shanghai fangyan yufa yanjiu (Studies on the grammar of Shanghainese dialect). Huadong Teachers University Publishing House.

XU, LJEJIONG (1985/86): Towards a lexical-thematic theory of control. In: The Linguistic Review 5: 345-376.

XU, LIEJIONG (1994): Yu kong yulei youguan de yixie hanyu yufa xianxiang (Phenomena in Chinese grammar related to empty categories). In: Zhongguo yuwen 242 (5): 321-329.

YEH, LING-HSIA (1995): Focus, metalinguistic negation and contrastive negation. In: Journal of Chinese Linguistics 23 (2): 42-75.

YUAN, YULIN (1993): Zheng-fan wenju ji xiangguan de leixingxue canxiang (Alternative questions and related typological parameters). In: Zhongguo Yuwen 233: 103-111.

YUAN, YULIN (2000): Hanyu huati de yufa diwei he yufahua guocheng (On the Grammatical Status and Degree of Grammaticalization of Topic in Chinese), paper at the International 
Symposium on Topic and Focus in Chinese, The Hong Kong Politechnic University, June $21-22,2000$.

Zhang, Ning (1997): Syntactic Dependencies in Mandarin Chinese. Ph. D. Dissertation, University of Tornoto.

ZHANG, NING (2000): Object shift in Mandarin Chinese. In: Journal of Chinese Linguistics 28: 201-246.

ZHANG, BOJIANG \& Fang, Mei (1996): Hanyu gongnengyufa yanjiu (Studies in Chinese functional grammar). Nanchang: Jiangxi Educational Publishing House.

ZHANG, BOJIANG (1999): Hanyu-de yiwenju-de gongneng jieshi (On the functions of Chinese question sentences). In: F. Xing (ed.), Han yu fa tedian mian mian guan (An overview of the peculiarities of Chinese grammar), 291-303. Beijing: The Beijing Language and Culture University Publishing House.

ZOU, KE (1993): The Syntax of the Chinese BA-Construction. In: Linguistics 31: 715-736. 
